\title{
Simulation of submillimetre atmospheric spectra for characterising potential ground-based remote sensing observations
}

\author{
Emma C. Turner ${ }^{1, a}$, Stafford Withington ${ }^{1}$, David A. Newnham ${ }^{2}$, Peter Wadhams ${ }^{3}$, Anna E. Jones ${ }^{2}$, and Robin Clancy ${ }^{3}$ \\ ${ }^{1}$ Cavendish Laboratory, University of Cambridge, Madingley Road, Cambridge, CB3 0HE, UK \\ ${ }^{2}$ British Antarctic Survey, High Cross, Madingley Road, Cambridge, CB3 OET, UK \\ ${ }^{3}$ Department of Applied Mathematical and Theoretical Physics, University of Cambridge, \\ Wilberforce Road, Cambridge, CB3 0WA, UK \\ anow at: Met Office, FitzRoy Road, Exeter EX1 3PB, UK \\ Correspondence to: Emma C. Turner (emma.turner@metoffice.gov.uk)
}

Received: 19 May 2016 - Published in Atmos. Meas. Tech. Discuss.: 23 June 2016

Revised: 13 October 2016 - Accepted: 27 October 2016 - Published: 14 November 2016

\begin{abstract}
The submillimetre is an understudied region of the Earth's atmospheric electromagnetic spectrum. Prior technological gaps and relatively high opacity due to the prevalence of rotational water vapour lines at these wavelengths have slowed progress from a ground-based remote sensing perspective; however, emerging superconducting detector technologies in the fields of astronomy offer the potential to address key atmospheric science challenges with new instrumental methods. A site study, with a focus on the polar regions, is performed to assess theoretical feasibility by simulating the downwelling (zenith angle $=0^{\circ}$ ) clearsky submillimetre spectrum from $30 \mathrm{~mm}(10 \mathrm{GHz})$ to $150 \mu \mathrm{m}$ $(2000 \mathrm{GHz})$ at six locations under annual mean, summer, winter, daytime, night-time and low-humidity conditions. Vertical profiles of temperature, pressure and 28 atmospheric gases are constructed by combining radiosonde, meteorological reanalysis and atmospheric chemistry model data. The sensitivity of the simulated spectra to the choice of water vapour continuum model and spectroscopic line database is explored. For the atmospheric trace species hypobromous acid ( $\mathrm{HOBr}$ ), hydrogen bromide ( $\mathrm{HBr})$, perhydroxyl radical $\left(\mathrm{HO}_{2}\right)$ and nitrous oxide $\left(\mathrm{N}_{2} \mathrm{O}\right)$ the emission lines producing the largest change in brightness temperature are identified. Signal strengths, centre frequencies, bandwidths, estimated minimum integration times and maximum receiver noise temperatures are determined for all cases. $\mathrm{HOBr}, \mathrm{HBr}$ and $\mathrm{HO}_{2}$ produce brightness temperature peaks in the $\mathrm{mK}$ to $\mu \mathrm{K}$ range, whereas the $\mathrm{N}_{2} \mathrm{O}$ peaks are in the $\mathrm{K}$ range. The optimal submillimetre remote sensing lines for the four
\end{abstract}

species are shown to vary significantly between location and scenario, strengthening the case for future hyperspectral instruments that measure over a broad wavelength range. The techniques presented here provide a framework that can be applied to additional species of interest and taken forward to simulate retrievals and guide the design of future submillimetre instruments.

\section{Introduction}

Atmospheric emission at submillimetre wavelengths which constitutes part of the longwave energy budget is rich in information on water vapour, trace gases and ice clouds. First reviewed by Harries (1977), the author notes in his complementary paper on the potential for submillimetre radiometry that atmospheric measurement in this region has received relatively little attention compared with other bands such as the infrared (Harries, 1980). After nearly four decades this is still the case. At wavelengths shorter than one millimetre, atmospheric absorption is dominated by the pure rotational transitions of water vapour, which can obscure the signals of other constituents from a ground-based vantage point. The wider availability of transmissive atmospheric windows at both longer and shorter wavelengths has, therefore, put the submillimetre region at a disadvantage. Additionally, a gap in the technology between the electronic and optical devices developed for the microwave and infrared respectively, the socalled "terahertz gap" (Sirtori, 2002), has slowed progress. 
However, recent developments in astronomy technology, particularly in the field of superconductivity - see the SPIE conference proceedings series on Millimeter, Submillimeter, and Far-Infrared Detectors and Instrumentation for Astronomy (I-VII) (Holland and Zmuidzinas, 2012, 2014; Arnold et al., 2010; Duncan et al., 2008; Zmuidzinas et al., 2004; Phillips and Zmuidzinas, 2003) - are providing new opportunities to open this spectral region up to the atmospheric science community.

The astronomical community has been motivated to overcome these difficulties as submillimetre sources from outer space contain critical information about the early universe (Phillips, 1988). Several large-scale observing systems have been built to house instruments that measure at these wavelengths (see Table 1 of Schneider et al., 2009). For example, the Atacama Large Millimetre/submillimeter Array (ALMA) located in the Atacama Desert, Chile which became operational in 2011 comprises 66 radio telescopes and is the largest astronomical project in existence (Wootten and Thompson, 2009). Using existing radio telescope sites combined with emerging technology offers a novel and elegant way for the atmospheric sciences to gain insights into an underexploited wavelength range.

This paper presents the requirements for measuring atmospheric species from the ground using their submillimetre spectra. The aims of this work are to develop a methodology for simulating clear-sky submillimetre $(10-2000 \mathrm{GHz})$ atmospheric spectra and determining optimal spectral lines and instrument characteristics for ground-based remote sensing of atmospheric trace species. We also identify complementary areas of improvement for spectroscopic reference data. A strategy is established for theoretically characterising the principle measurement requirements for a sample of compounds at selected sites using forward radiative transfer simulations. It should be noted that, while we can easily eliminate clouds in the model world, this could contaminate signals unless carefully screened for. We focus on polar locations, as these are regions that are particularly vulnerable to climate change (Marshall et al., 2014; Serreze and Barry, 2011) and have unique atmospheric conditions that present a challenge for instrument deployment. For example, when dealing with a near-horizon view over ice sheets, the air in the first few metres just above the ice surface in winter often has poor visibility and high internal reflectivity because of so-called "diamond dust", a mist of tiny ice crystals in the atmosphere. We use a zenith angle of zero and a twodimensional vertical column atmosphere for all calculations in this preliminary study as we are able to construct highly accurate profiles using radiosonde observations which are only released at a single point at each location. However, a full characterisation where a target receiver system is identified would require a three-dimensional atmosphere and simulations with greater zenith angles, appropriate to the operational specifications of the receiver, in order to maximise the signal-to-noise ratio.
Four molecules, hydrogen bromide ( $\mathrm{HBr}$ ), hypobromous acid ( $\mathrm{HOBr})$, the hydroperoxyl radical $\left(\mathrm{HO}_{2}\right)$ and nitrous oxide $\left(\mathrm{N}_{2} \mathrm{O}\right)$, are used as example species, chosen because they cover a range of scientific applications, geographical distributions and signal intensities. They are climatically important for the following reasons. $\mathrm{HBr}$ and $\mathrm{HOBr}$ are part of the bromine cycle, which is of interest because active forms of bromine ( $\mathrm{BrO}$ and $\mathrm{Br}$ ) have been shown to strongly catalyse ozone depletion (McConnell et al., 1992). As well as anthropogenic bromine compounds (which contribute to stratospheric ozone destruction), there are natural sources of bromine which destroy ozone in the troposphere. At high latitudes these sources are associated with the polar sea ice zone, but the precise sources and mechanisms of release are not yet clear (Abbatt et al., 2012; Simpson et al., 2007). HBr is the main bromine reservoir, thus providing a means of removing $\mathrm{Br}$ from the atmosphere through wet and dry deposition in the lower troposphere. Continuous measurements of $\mathrm{HBr}$, particularly in the polar troposphere, would help constrain the distribution and origins of bromine. Similarly $\mathrm{HOBr}$ is an important intermediary product in the ozone destruction process, which is photolysed to produce $\mathrm{Br}$ and hydroxyl radicals $(\mathrm{OH})$ without reforming the original ozone it was constructed with. Measuring atmospheric $\mathrm{HOBr}$ is particularly challenging because of its low concentration and short lifetime ( $\sim 10 \mathrm{~min})$, and it has only recently been measured in isolation (Liao et al., 2012). Both bromine species have weak spectral signals due to their low concentrations; however, in the case of $\mathrm{HOBr}$, no spectral transitions have been measured yet above $9440 \mathrm{GHz} . \mathrm{HO}_{2}$ is also part of the bromine and chlorine cycles, where it is a precursor for $\mathrm{HBr}$ and $\mathrm{HOBr}$ amongst other reactions. It is a member of the $\mathrm{HO}_{x}$ chemical family $\left(\mathrm{HO}_{x}=\mathrm{HO}_{2}+\mathrm{OH}+\mathrm{H}\right)$ which catalyses ozone destruction in the upper stratosphere and mesosphere (Clancy et al., 1994). Work to quantify the role of $\mathrm{HO}_{2}$ in this process is ongoing (Millán et al., 2015). $\mathrm{N}_{2} \mathrm{O}$ is a greenhouse gas that is estimated to produce the third largest radiative forcing (excluding water vapour) of all anthropogenic gases behind carbon dioxide and methane (Pachauri et al., 2014). It is an extremely important ozone-depleting substance and is expected to remain so throughout the 21st century (Ravishankara et al., 2009). Because of its long lifetime, it is well mixed throughout the troposphere and has a significantly stronger spectral signal than the other three target gases in this study.

Like most regions in the electromagnetic spectrum, submillimetre wavelengths, alternatively known as terahertz frequencies, have arbitrarily defined boundaries and, depending on those chosen, can overlap with parts of the far-infrared as well as the millimetre/microwave, despite its name. For the present study we define the submillimetre as $30 \mathrm{~mm}$ $(10 \mathrm{GHz})$ to $150 \mu \mathrm{m}(2000 \mathrm{GHz})$, incorporating some of the longer wavelengths, which is beneficial when considering emerging technologies in this area. For the remainder of this publication, units of frequency are used. 
The rest of this paper is organised as follows. A review of atmospheric submillimetre observations performed to date is presented in Sect. 2. Section 3 describes the method used to construct input climatologies, simulate radiances and determine measurement characteristics. Resulting background simulations over a broad frequency range are presented in Sect. 4. Signals for the four sample gases are shown in Sect. 4.2 and each one discussed in turn. Finally, all signal parameters and measurement requirements are listed for each species in Tables 5, 6, 7 and 8 .

\section{Submillimetre atmospheric observations}

The concept of combining astronomy with atmospheric observations has been demonstrated by the Submillimeter and Millimeter Radiometer (SMR) (Frisk et al., 2003), a primary payload of the Odin satellite (Nordh et al., 2003) launched in 2001. SMR has four tunable heterodyne receivers that cover frequencies between 486-504 and 541-581 GHz and a fifth fixed channel at $118.75 \mathrm{GHz}$. It shares observation time between astronomy mode and terrestrial mode and has been instrumental in observing atmospheric constituents such as $\mathrm{ClO}, \mathrm{N}_{2} \mathrm{O}, \mathrm{HNO}_{3}, \mathrm{O}_{3}$, water vapour and ice clouds (Urban et al., 2005; Ekström et al., 2007). A similar approach was employed by the Microwave Instrument for the Rosetta Orbiter (MIRO) on the Rosetta spacecraft, which was temporarily diverted from its primary purpose to rendezvous with the 67P/Churyumov-Gerasimenko comet, in order to measure the terrestrial atmosphere during a scheduled Earth flyby (Jiménez et al., 2013). Data recorded in MIRO's channels centred at 183, 190, 557 and $562 \mathrm{GHz}$ were used to test the instruments performance against expected results from radiative transfer models and measurements from the Earth Observing System Microwave Limb Sounder (EOS MLS). EOS MLS is a submillimetre instrument dedicated to terrestrial observations which has operated on the Aura satellite since 2004 (Waters et al., 2006). It has five heterodyne radiometers centred on $118,190,240,640 \mathrm{GHz}$ and $2.5 \mathrm{THz}$, which have been used to obtain profiles of stratospheric and mesospheric trace gases including $\mathrm{HCl}, \mathrm{HOCl}$, $\mathrm{N}_{2} \mathrm{O}, \mathrm{OH}, \mathrm{CO}$ and volcanic $\mathrm{SO}_{2}$ (Froidevaux et al., 2006). The submillimetre atmospheric spectrum was also investigated during 7 months of observations made by the $\mathrm{Su}$ perconducting Submillimeter-Wave Limb-Emission Sounder (SMILES), deployed on the International Space Station. SMILES recorded terrestrial radiation in three bands covering 624.32-625.52, 625.12-626.32 and 649.12-650.32 GHz using superconductor-insulator-superconductor (SIS) mixers for sensitive measurements from which vertical profiles of $\mathrm{HCl}, \mathrm{ClO}, \mathrm{HO}_{2}, \mathrm{BrO}, \mathrm{HNO}_{3}$ and isotopes of $\mathrm{O}_{3}$ have been retrieved (Kikuchi et al., 2010).

The submillimetre part of the spectrum has a unique value in the passive remote sensing of cirrus clouds owing to the comparable size of ice particles and wavelengths between 300-1000 GHz, leading to enhanced attenuation and possi- ble detection (Prigent et al., 2006; Yang et al., 2003). There is a pressing need to characterise ice clouds as they exert a strong influence on the radiative energy balance yet many uncertainties associated with their microphysical properties remain, particularly those surrounding global distributions of ice water path and particle size (Buehler et al., 2012). Prototype instruments developed to measure ice cloud properties in the submillimetre include the Far Infrared Sensor for Cirrus (FIRSC) (Vanek et al., 2001; Evans et al., 1999), the Compact Instrument for Longwave Cirrus Observations (CILCO) (Hayton and Ade, 2007) and the International SubMillimetre Airborne Radiometer (ISMAR) (Charlton et al., 2009). The new generation of ESA/EUMETSAT Earth Observation satellites, Meteorological Operational Satellite Second Generation (MetOp-SG), scheduled for launch in 2022, will carry the Ice Cloud Imager (ICI) which will measure cloud ice water path in the $183-664 \mathrm{GHz}$ range (Thomas et al., 2012). Additionally, two microwave instruments will fly alongside ICI; Microwave Sounder (MWS) and Microwave Imager (MWI), all three of which benefit from state-of-the-art Schottky diode-based mixers (Thomas et al., 2014). The analysis in the remainder of this study is restricted to clear-sky atmospheric applications of the submillimetre.

While satellite and spacecraft observations have the advantage of large-scale coverage and a favourable vantage point to detect and profile the vertical distributions of high-altitude gases they are limited in terms of their payload, and once in orbit cannot be easily adjusted. Setting up a mission is also time and financially costly, typically spanning decades between concept and launch, by which time technology has moved on. Instruments designed to operate from the ground can offer greater flexibility and are also substantially less expensive to build, deploy and operate. Whereas polar orbiting satellites will pass over any one high-latitude point a maximum of twice a day, Earth-bound instruments benefit from continuous measurements enabling the local diurnal variability of atmospheric parameters to be studied. Although no ground-based instrument has been built by the atmospheric community to measure the full submillimetre spectrum to date, this has been achieved by Fourier transform spectrometers (FTS) which are used as a calibration tool for astronomical telescopes (Matsushita and Matsuo, 2003; Pardo et al., 2004). For example, the Smithsonian Astronomical Observatory (SAO) submillimetre FTS measures continuously from 300-3500 at a $3 \mathrm{GHz}$ apodized resolution (Paine et al., 2000; Paine and Turner, 2013) and has been employed by Turner et al. (2012) for studying the terrestrial atmosphere above the Atacama Desert. Additionally, Pardo et al. (2002) used the Caltech Submillimeter Observatory (CSO) FTS (Pardo et al., 2001b; Serabyn et al., 1998), over the 350-1100 GHz range to constrain estimates of the water vapour continuum and to refine the Atmospheric Transmission at Microwaves (ATM) radiative transfer model (Pardo et al., 2001a). Other such 


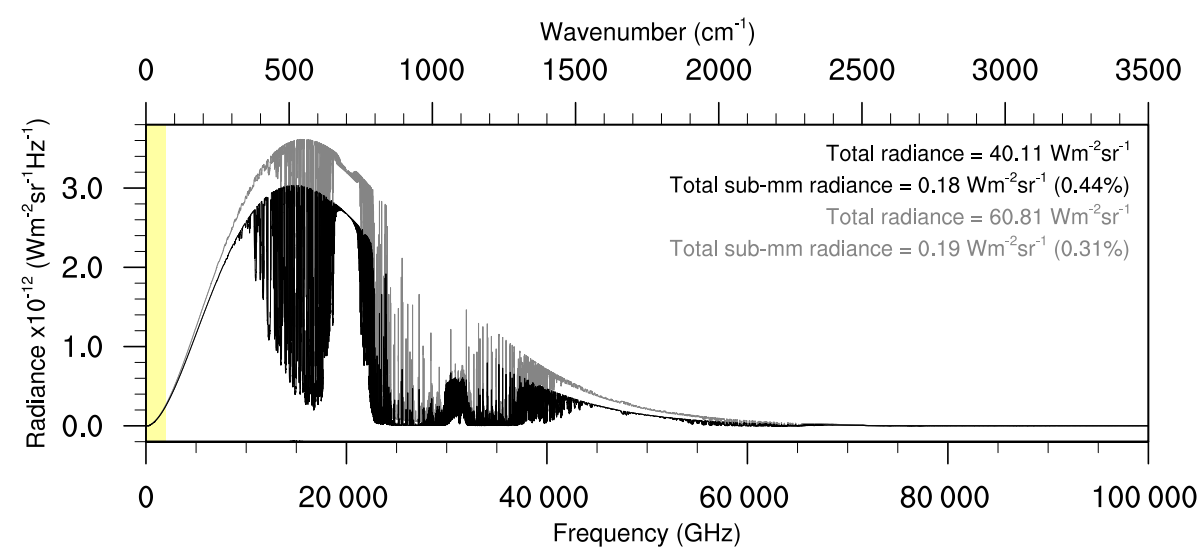

Figure 1. The simulated downwelling spectral radiance (zenith angle $=0^{\circ}$ ) received at the Earth's surface over the entire longwave range $(1$ GHz sampling resolution). The submillimetre region $(10-2000 \mathrm{GHz})$ is shaded in yellow. Calculations for two polar locations are shown: a high, dry Arctic case (Summit, Greenland - 3216 m a.m.s.l., black) and an Antarctic coastal case just above sea level (Rothera, Antarctica $16 \mathrm{~m}$ a.m.s.l., grey). For full details of the simulations see Sect. 3.

instruments, for example, the South Pole FTS (Chamberlin et al., 2003) could also potentially be used in this manner.

Accurate quantification of the different components of the Earth's energy balance measured at the surface and top of atmosphere (TOA) is of vital importance for monitoring climate change (Stephens and L'Ecuyer, 2015; Stephens et al., 2012). Improvements are the result of using precise, well calibrated measuring equipment in a wide range of locations with increased spectral coverage and finer sampling resolution. There has been increased interest within the climate sciences in the far-infrared spectrum, typically taken as $2000-20000 \mathrm{GHz}(15-150 \mu \mathrm{m})$, e.g. see Harries et al. (2008); Turner et al. (2015). This has also been sparsely measured in the atmosphere for similar reasons to those of the submillimetre, despite representing up to half of the total outgoing longwave radiation and three quarters of the total incoming longwave radiation. Recent instruments designed to fill this gap include the Atmospheric Emitted Radiance Interferometer (AERI) (Turner et al., 2004), the Radiation Explorer in the Far InfraRed (REFIR) (Esposito et al., 2007; Palchetti et al., 2008), the Tropospheric Airborne Fourier Transform Spectrometer (TAFTS) Green et al. (2012), the Interferometer for Basic Observation of Emitted Spectral Radiance of the Troposphere (I-BEST) Masiello et al. (2012) and the Far-Infrared Spectroscopy of the Troposphere (FIRST) instrument (Mlynczak et al., 2004). Whereas all of these instruments were designed to make consecutive measurements covering a wide spectral range, existing submillimetre instruments typically measure in narrow channels (excepting the SAO submillimetre FTS), in line with their primary purpose of detecting preselected lines of specific gases. However, for the purpose of studying the submillimetre's contribution to the Earth's energy budget broadband measurements are required.
Figure 1 shows the submillimetre region relative to the total downwelling longwave spectrum for two polar locations. At frequencies where the curve resembles the shape of a Planck function the atmosphere is opaque, whereas in atmospheric window regions, such as around 15000, 27500 and $35000 \mathrm{GHz}$, the radiance drops. Note that radiance is the radiant flux received per unit solid angle and is hence a directional quantity. The total energy received at any point will include contributions from all directions. The submillimetre's fractional contribution to the total energy incident at the ground from the nadir direction is small (below $0.5 \%$ ), but not insignificant, accounting for a larger proportion of the total radiance in colder and drier conditions (black line). To put this into context the downwards flux resulting from an isotropic radiance field (Flux $=\pi$ Radiance) for both of these cases is about $0.6 \mathrm{Wm}^{-2}$, which is approximately equal to the total energy imbalance of the Earth (Smith et al., 2015; Hansen et al., 2011). For maximum accuracy across the whole longwave spectrum the submillimetre would benefit from the same rigorous treatment applied to other regions to provide confidence that it is sufficiently well represented by radiative transfer algorithms in line-by-line and global climate models. Progress in this regard is the result of radiative closure studies which are designed to "minimise differences" between models and observations, e.g. (Delamere et al., 2010; Turner et al., 2004; Clough et al., 1994). In brief, these studies involve making spectral measurements across the frequency range of interest while simultaneously characterising the surrounding atmospheric state, often with concurrent radiosonde launches, the data of which are used to drive radiative transfer calculations to compare with the observed radiances. Residual analysis is then used to improve the models by adjusting spectroscopic and continuum parameters to better fit the measurements. In clear-sky simulations the main focus of these experiments at frequencies in opaque 
regions is to test water vapour absorption and emission parameters, both line related and continua, the latter of which is known to dominate model uncertainties (Delamere et al., 2010).

The continuum contribution is what remains after deducting the radiance produced by allowed spectral transitions, which takes the form of a slowly varying function with respect to frequency (Clough et al., 1989). The strongest effects are seen in the atmospheric windows, where the continuum is often the main contributor to the total radiance. The functional form and underlying theory remain an area of scientific uncertainty (Shine et al., 2012) and as such it is parameterised semi-empirically in radiative transfer models in order to provide agreement with in situ measurements rather than resolving the underlying processes explicitly. Hence, in order to improve and validate its representation at all frequencies radiative closure studies are required in every spectral region in which water vapour is radiatively active. To date, there have been water vapour continuum closure studies in the infrared (Mlawer et al., 2012), far infrared (Fox et al., 2015; Masiello et al., 2012; Delamere et al., 2010; Tobin et al., 1999), microwave (Wentz and Meissner, 2016; Payne et al., 2011; Turner et al., 2009) and a single study in the submillimetre region between $350-1100 \mathrm{GHz}$ (Pardo et al., 2001b). To our knowledge, the equivalent has not been performed in the region between $1100-10500 \mathrm{GHz}$. Terahertz continua have been measured under controlled conditions in the laboratory (Slocum et al., 2013; Podobedov et al., 2008); however, the exact atmospheric conditions and composition of the air is difficult to reproduce without in situ measurements. Therefore, continuum models at submillimetre wavelengths are determined by analytical continuation of values determined in other regions. Given the large uncertainty in these extrapolated values, which will be exacerbated with altered water vapour concentrations, such as the increased amounts in the upper troposphere predicted under climate change (Chung et al., 2014), radiative closure studies would be a highly beneficial test of the representation of this spectral band.

In addition to ice clouds and water vapour, the submillimetre atmospheric spectrum is rich in lines arising from primarily the pure rotational transitions of many different atmospheric gases, some of which do not have observed lines at other wavelengths. Though many of these signals are weak against the background atmosphere compared with those in the infrared, for example, advances in technology may offer the potential for retrieving vertical gas concentrations with equivalent or better accuracy than previously achieved, even from the ground. Selecting the optimum line (or lines) to characterise the distribution of a particular molecule is a vital step which can then be used to provide a framework for developing future instruments. Previous examples of this approach are Kasai et al. (2006), who simulated the observational capabilities of various submillimetre bands for identifying ozone isotopes prior to the past SMILES mission,
Manago et al. (2014), who scoped $\mathrm{BrO}$ and $\mathrm{HOCl}$ for the planned SMILES-2 mission and Urban, 2003, who determined the optimum signals of $\mathrm{HBr}, \mathrm{BrO}, \mathrm{HOCl}$ and $\mathrm{HO}_{2}$ for potential future satellite missions, as did Jiménez et al. (2007) and Buehler et al. (2007) with regards to cloud ice. For ground-based remote sensing, Ryan and Walker (2015) simulate measurements of $\mathrm{HNO}_{3}, \mathrm{O}_{3}, \mathrm{~N}_{2} \mathrm{O}$ and $\mathrm{ClO}$ for the proposed Arctic SPÉIR instrument which will operate in the frequency range below $300 \mathrm{GHz}$. Unlike these previous studies the present work does not apply retrieval algorithms to obtain the vertical distributions of each gas from the identified signals, which is instead left for future studies.

\section{Methodology and data}

The downwelling spectrum at submillimetre wavelengths is dominated by the vertical distribution of pressure, temperature, water vapour, nitrogen, oxygen and ozone, which we term the "background" atmosphere. Ozone is included because of its strong radiative properties in this frequency range. Constructing accurate background atmospheres is crucial when characterising particular locations, as these parameters can vary considerably between sites. For example, if the water vapour profile is poorly characterised, e.g. due to local variations in humidity and temperature within clouds, this will produce changes in the signal received at the ground (in the real world this can be modelled by adjusting the tropospheric opacity/water vapour to fit the baseline atmospheric brightness temperature). The method adopted is described in Sect. 3.1. Added to the background atmosphere are a further 24 gaseous species, including $\mathrm{HOBr}, \mathrm{HBr}, \mathrm{HO}_{2}$ and $\mathrm{N}_{2} \mathrm{O}$, to produce what we term the "complete" atmosphere, the sources of which are detailed in Sect. 3.2. Climatologies of these 30 parameters are constructed for input to a line-by-line radiative transfer forward model, which is configured as described in Sect. 3.3. Simulated downwelling brightness temperatures and transmissions are produced at a sampling resolution of $0.5 \mathrm{GHz}$ initially to perform a survey of the whole submillimetre region. To isolate the radiative contribution of each species of interest, an equivalent simulation is performed which omits it, so the residual between the two sets of radiances provides an estimate of the atmospheric "signal" of the species separated from the signal from the rest of the model atmosphere. The full spectral surveys provide a guide to selecting target lines based on the signal strength of the source molecule, which are then analysed in more detail by performing a further simulation at a higher-frequency resolution in the narrow region surrounding the line. The procedure followed to determine measurement characteristics for each line identified is described in Sect. 3.3.

\subsection{Background climatologies}

An overview of the chosen sites at which downwelling radiances are simulated is given in Table 1, along with the rea- 
Table 1. Sites selected for submillimetre characterisation with observational sources.

\begin{tabular}{|c|c|c|c|c|}
\hline Site & Coordinates & Altitude (m) & Reason for selection & Observational data \\
\hline $\begin{array}{l}\text { Atacama } \\
\text { Desert, Chile }\end{array}$ & $\begin{array}{l}23^{\circ} 1^{\prime} 9.42^{\prime \prime} \mathrm{S} \\
67^{\circ} 45^{\prime} 11.44^{\prime \prime} \mathrm{W}\end{array}$ & 5055 & $\begin{array}{l}\text { Site of the Atacama Large } \\
\text { Millimeter/submillimeter Array } \\
\text { (ALMA) radio telescope which } \\
\text { has a very high elevation and } \\
\text { dry surroundings. }\end{array}$ & $\begin{array}{l}\text { AIR 5A radiosondes from October } \\
\text { 1998-May 2001, replaced by } \\
\text { Vaisala RS80 radiosondes from } \\
\text { May-December } 2001 \text { as part of the } \\
\text { Chajnantor radiosonde campaign } \\
\text { (Giovanelli et al., 2001). }\end{array}$ \\
\hline
\end{tabular}

\begin{tabular}{|c|c|c|c|}
\hline Halley, & $75^{\circ} 36^{\prime} 16^{\prime \prime} \mathrm{S}$ & 43 & British Antarctic Survey (BAS) \\
\hline Antarctica & $26^{\circ} 12^{\prime} 32^{\prime \prime} \mathrm{W}$ & & $\begin{array}{l}\text { research station located on an } \\
\text { ice shelf. The site has cold and } \\
\text { dry conditions. }\end{array}$ \\
\hline
\end{tabular}

Synoptic data from MAWSON weather station from 2000-2004, MILOS 520 automatic weather station from 20052006 and Campbell Scientific automatic weather station from 2007-2014. Vaisala RS80 radiosondes from 20002006 and Vaisala RS92 radiosondes from 2007-2014.

\begin{tabular}{|c|c|c|c|}
\hline $\begin{array}{l}\text { Mauna Kea, } \\
\text { Hawaii }\end{array}$ & $\begin{array}{l}19^{\circ} 49^{\prime} 14^{\prime \prime} \mathrm{N} \\
155^{\circ} 28^{\prime} 05^{\prime \prime} \mathrm{W}\end{array}$ & 4205 & $\begin{array}{l}\text { Site of the Mauna Kea Obser- } \\
\text { vatories which is home to } 12 \\
\text { radio telescopes at a high eleva- } \\
\text { tion. }\end{array}$ \\
\hline
\end{tabular}

Commercial automatic weather stations (AWSs) measurements made at $2 \mathrm{~m}$ above the ground from Thirty Metre Telescope (TMT) site testing (Schöck et al., 2009). Produced by Monitor Sensors.

\begin{tabular}{llll}
\hline Rothera, & $67^{\circ} 33^{\prime} 57^{\prime \prime} \mathrm{S}$ & $16 \quad \begin{array}{l}\text { British Antarctic Survey (BAS) } \\
\text { research station in a coastal lo- } \\
\text { Antarctica }\end{array} \quad 68^{\circ} 07^{\prime} 43^{\prime \prime} \mathrm{W}$ & $\begin{array}{l}\text { cation with cold maritime sur- } \\
\text { roundings. }\end{array}$
\end{tabular}

Synoptic data from MAWSON weather station from 2000-2004, MILOS 520 automatic weather station from 20052009 and Just Another Weather Station (JAWS) from 2010-2014. Vaisala RS80 radiosondes from 2000-2006 and Vaisala RS92 radiosondes from 20072014.

\begin{tabular}{|c|c|c|c|c|}
\hline $\begin{array}{l}\text { Summit, } \\
\text { Greenland }\end{array}$ & $\begin{array}{l}72^{\circ} 35^{\prime} 0^{\prime \prime} \mathrm{N} \\
38^{\circ} 27^{\prime} 0^{\prime \prime} \mathrm{W}\end{array}$ & 3216 & $\begin{array}{l}\text { Research station on the Green- } \\
\text { land ice sheet with a high ele- } \\
\text { vation and cold, dry conditions. }\end{array}$ & $\begin{array}{l}\text { Vaisala RS92-K radiosondes from the } \\
\text { Integrated Characterization of Energy, } \\
\text { Clouds, Atmospheric State and Precipi- } \\
\text { tation at Summit (ICECAPS) program } \\
\text { (Shupe et al., 2013). }\end{array}$ \\
\hline $\begin{array}{l}\text { Thule, } \\
\text { Greenland }\end{array}$ & $\begin{array}{l}76^{\circ} 31^{\prime} 52^{\prime \prime} \mathrm{N} \\
68^{\circ} 42^{\prime} 11^{\prime \prime} \mathrm{W}\end{array}$ & 77 & $\begin{array}{l}\text { US Airbase and initial site of } \\
\text { the planned Greenland Tele- } \\
\text { scope (GLT). Cold coastal con- } \\
\text { ditions. }\end{array}$ & $\begin{array}{l}\text { Vaisala RS } 80 \text { VLF radiosonde launches } \\
\text { compiled by the Met Office and } \\
\text { archived with BADC } \\
\text { (MetOffice, 2006). }\end{array}$ \\
\hline
\end{tabular}

sons for their selection. Broadly, these reasons are either high elevation and/or cold conditions, giving the benefit of low water vapour concentrations at ground level and in the troposphere, and the availability of existing science infrastructure at the site. Particular care is taken in constructing profiles as features such as irregular orography and temperature and humidity inversions, which are particularly prevalent in the four high-latitude sites selected (Zhang et al., 2011) and can have a large effect on submillimetre radiative transfer. Modelled quantities calculated on a fixed grid of locations do not accurately reproduce the level of detail captured by in situ observational systems.
For all sites, radiosonde data are obtained from various previous campaigns, apart from Mauna Kea in Hawaii where only ground level meteorological data are available. For Halley and Rothera, separate surface synoptic measurements taken at the time of balloon launches are used for the lowest level of each radiosonde profile. For diurnal consistency across all sites, data are subselected to retain only local noontime measurements or, where data availability is limited, as close as possible within a $3 \mathrm{~h}$ time window. For the Greenland campaigns radiosondes were regularly launched between 11:00 and 12:00, for the Antarctic locations times tended to be between 10:00 and 12:00, for Mauna Kea 12:00 was 


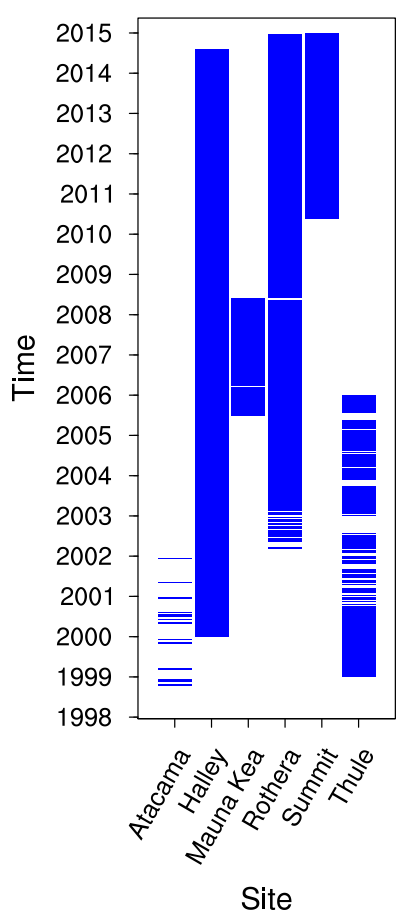

Figure 2. Time coverage of the background climatologies defined by the available radiosonde data from each site. Instrument details are given in Table 1.

achievable daily as the weather station monitors recorded continuously, and the majority of balloon launches from Atacama were in the afternoon from 13:00. The time period covered by each data set is shown in Fig. 2. All available data are used to construct profiles at each site to obtain the most typical representation of atmospheric conditions possible.

As many of the species of interest are present in significant abundance in the stratosphere and above, which is beyond the coverage of most in situ observations, ERA-Interim reanalysis data (Dee et al., 2011) are spliced on top of each available radiosonde profile of water vapour and temperature. This is the latest global atmospheric reanalysis produced by the European Centre for Medium-Range Weather Forecasts (ECMWF) which is calculated at a T255 spectral resolution $\left(\sim 0.7^{\circ}\right.$ latitude $\times \sim 0.7^{\circ}$ longitude $)$ at 60 vertical pressure levels up to $0.1 \mathrm{hPa}$. The temporal resolution is 6 hourly in Coordinated Universal Time (UTC). The ERAInterim profile associated with each radiosonde launch is the one closest to noon, after adjusting UTC for each site's local solar time. For the selected sites this is at 18:00 UTC, apart from Mauna Kea which is 00:00 UTC.

The water vapour profiles obtained using only radiosonde measurements and only ERA-Interim data are compared in Fig. 3. For the high-altitude sites, the Atacama Desert, Mauna Kea and Summit, the positions of the nearest ERAInterim grid point are at lower altitudes, yielding water vapour concentrations that are too high at ground level. Ra-
(a) Atacama
(b) Halley
(c) Mauna Kea

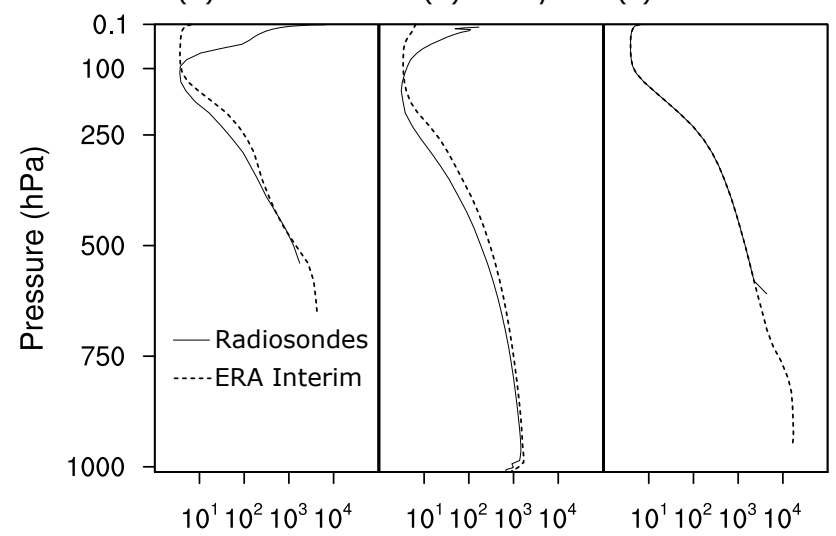

(d) Rothera

(e) Summit

(f) Thule

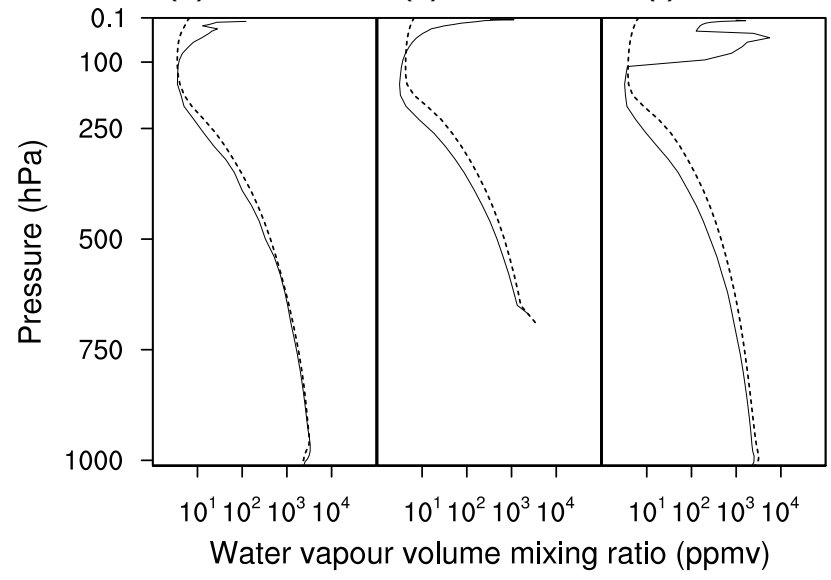

Figure 3. Climatologies of water vapour volume mixing ratio for radiosonde measurements (solid line) and ERA-Interim reanalysis data (dashed line) at all six sites (a-f). Radiosonde profiles are the average of all data available at each site. ERA-Interim data are subsampled to retain only the days when radiosondes were launched.

diosonde data at pressures below $100 \mathrm{hPa}$ seem to show spuriously high humidity values, the precise source of which is not clear. However, it is well known that radiosonde humidity measurements are less accurate at low temperatures (Wang et al., 2002). One reason for this inaccuracy is ice deposition on the sensor in an ice-supersaturated environment, which can lead to suspiciously elevated measurements well into the stratosphere (Miloshevich et al., 2006). Therefore, the final spliced profile combines observational data at lower levels up to a threshold of $100 \mathrm{hPa}$ and ERA-Interim between 100 and $0.1 \mathrm{hPa}$, with the exception of Mauna Kea profiles which are comprised entirely of reanalysis data, apart from the lowestaltitude level. Ozone profiles are derived solely from ERAInterim, which is sufficient because concentrations in the troposphere are very low compared to the stratospheric ozone layer. Molecular oxygen and nitrogen are set at the fixed values of 209000 and $781000 \mathrm{ppmv}$ respectively, as they are well mixed and show little variability below $64 \mathrm{~km}(0.1 \mathrm{hPa})$. 
Table 2. The six scenarios constructed from all spliced radiosonde and ERA-Interim reanalysis profiles. All constituent profiles are close to local noontime.

\begin{tabular}{ll}
\hline Scenario & Description \\
\hline Annual mean & All profiles \\
JJA & June, July and August \\
DJF & December, January and February \\
Day & Solar elevation angle greater than $5^{\circ}$ \\
Night & Solar elevation angle less than $5^{\circ}$ \\
$<10 \%$ PWV & Total column precipitable water vapour (PWV) \\
& less than or equal to the lower decile PWV \\
& of all profiles at a particular site \\
\hline
\end{tabular}

\section{Scenarios}

Spliced profiles are generated for each site under six different atmospheric scenarios, which are described in Table 2. For the low-humidity scenario $(<10 \% \mathrm{PWV})$, precipitable water vapour is calculated as the sum of the mean water vapour density over all layers at altitudes provided by the radiosonde data. For Mauna Kea, altitude information was not available so an estimate of PWV was made based on the method described by Smith (1966). As the PWV values are used solely for partitioning the data high absolute accuracy is not necessary. Figure 4 shows water vapour profiles, constructed as described in the previous section, for all scenarios at each site. All constituent profiles have a local time close to noon, hence the equatorial locations, Atacama and Mauna Kea, have no night scenario because there is little seasonal variation in daylight. Therefore, the day and the annual mean scenarios are one and the same. These scenarios have been chosen to incorporate the range of potential science interests of the molecules studied, some of which have strong seasonal variations at the high-latitude locations and strong diurnal cycles due to processes such as photolysis. For example, in the polar locations, humidity inversions are present in some of the scenarios shown in Fig. 4, but not others, which will have a strong effect on the simulated radiances. The lowhumidity case provides an estimate of the highest trace gas signal strengths that would occur in $10 \%$ of the year, which may be useful for measuring molecules with signals around the detection limit where a climatology rather than continual monitoring is sufficient.

\subsection{Trace gas climatologies}

All trace gases included in the complete atmosphere and their data sources are listed in Table 3. Certain brominated species such as $\mathrm{HBr}$ and $\mathrm{HOBr}$ have been sparsely measured, so for all four species of interest, climatologies are constructed from atmospheric chemistry climate model data. The model used is the stratospheric chemistry configuration of the UK Met Office Unified Model - UK Chemistry and Aerosol (UM-UKCA) (Morgenstern et al., 2009) which has an N48
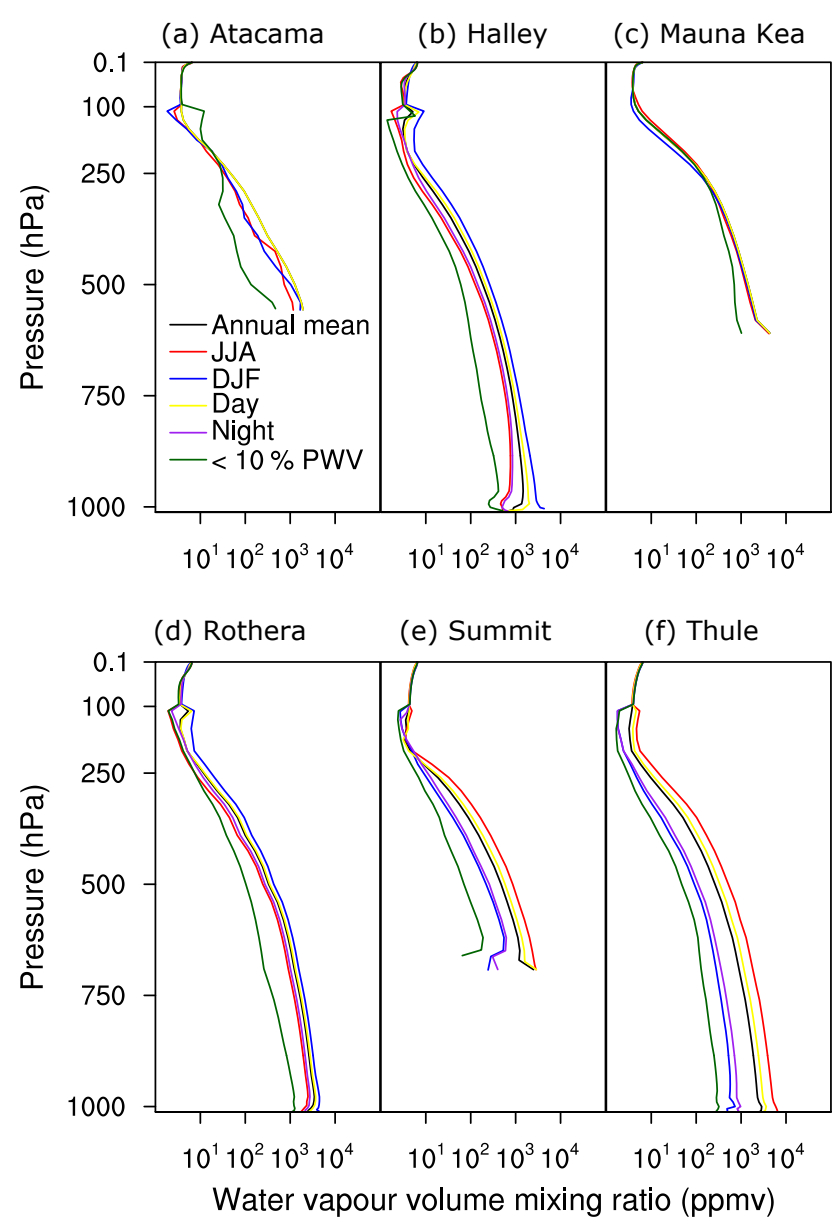

Figure 4. Climatologies of water vapour volume mixing ratio constructed with spliced radiosonde and ERA-Interim data showing the six scenarios described in Table 2 for all sites $(\mathbf{a}-\mathbf{f})$.

horizontal resolution $\left(2.5^{\circ}\right.$ latitude $\times 3.75^{\circ}$ longitude $)$ and 60 vertical levels extending up to $84 \mathrm{~km}$. The chemistry scheme has recently been updated with tropospheric bromine chemistry based on work with the pTOMCAT chemistry transport model (Yang et al., 2005, 2010, 2014). Data output at two UTC times, 01:00 and 13:00, for the whole of 2012 are adjusted to local solar times for each site and, as with ERA-Interim, the time closest to noon is retained. The zonal mean distributions of vertical concentration show considerable variation between each of the four species (Fig. 5). $\mathrm{HOBr}$ and $\mathrm{HBr}$ are the least concentrated with units on the order of parts per trillion by volume (pptv), $\mathrm{HO}_{2}$ is 3 times more abundant than this with units of parts per billion by volume (ppbv) and $\mathrm{N}_{2} \mathrm{O}$ is 6 times more concentrated at parts per million by volume (ppmv). The first three of these molecules have strong seasonal cycles; stratospheric $\mathrm{HOBr}$ abundance peaks in the polar winter due to prolonged periods of darkness, tropospheric $\mathrm{HBr}$ peaks over sea ice in the polar spring and $\mathrm{HO}_{2}$ peaks in the polar summer during the prolonged sunlit period. The UM-UKCA data provide an es- 
Table 3. Trace gases added to the background atmosphere (which includes $\mathrm{H}_{2} \mathrm{O}, \mathrm{O}_{3}, \mathrm{O}_{2}$ and $\mathrm{N}_{2}$ ) and their climatological sources.

\begin{tabular}{ll}
\hline Source & Constituents \\
\hline UM-UKCA $^{\text {a }}$ & $\mathrm{HOBr}, \mathrm{HBr}, \mathrm{HO}_{2}, \mathrm{HCOOH}, \mathrm{CH}_{3} \mathrm{OH}, \mathrm{N}_{2} \mathrm{O}$ \\
ECMWF-MACC6b & $\mathrm{CO}_{2}, \mathrm{CH}_{4}, \mathrm{CO}, \mathrm{H}_{2} \mathrm{CO}, \mathrm{SO}_{2}$ \\
AFGLc & $\mathrm{NO}, \mathrm{NO}_{2}, \mathrm{NH}_{3}, \mathrm{HNO}_{3}, \mathrm{OH}, \mathrm{HF}, \mathrm{HCl}, \mathrm{ClO}, \mathrm{OCS}, \mathrm{HOCl}, \mathrm{HCN}, \mathrm{CH}_{3} \mathrm{Cl}_{1} \mathrm{H}_{2} \mathrm{O}_{2}$ \\
\hline
\end{tabular}

${ }^{a}$ Unified Model - UK Chemistry and Aerosol (Met Office)

${ }^{\mathrm{b}}$ European Centre for Medium-Range Weather Forecasting - Monitoring Atmospheric Composition and Climate

c Air Force Geophysics Lab
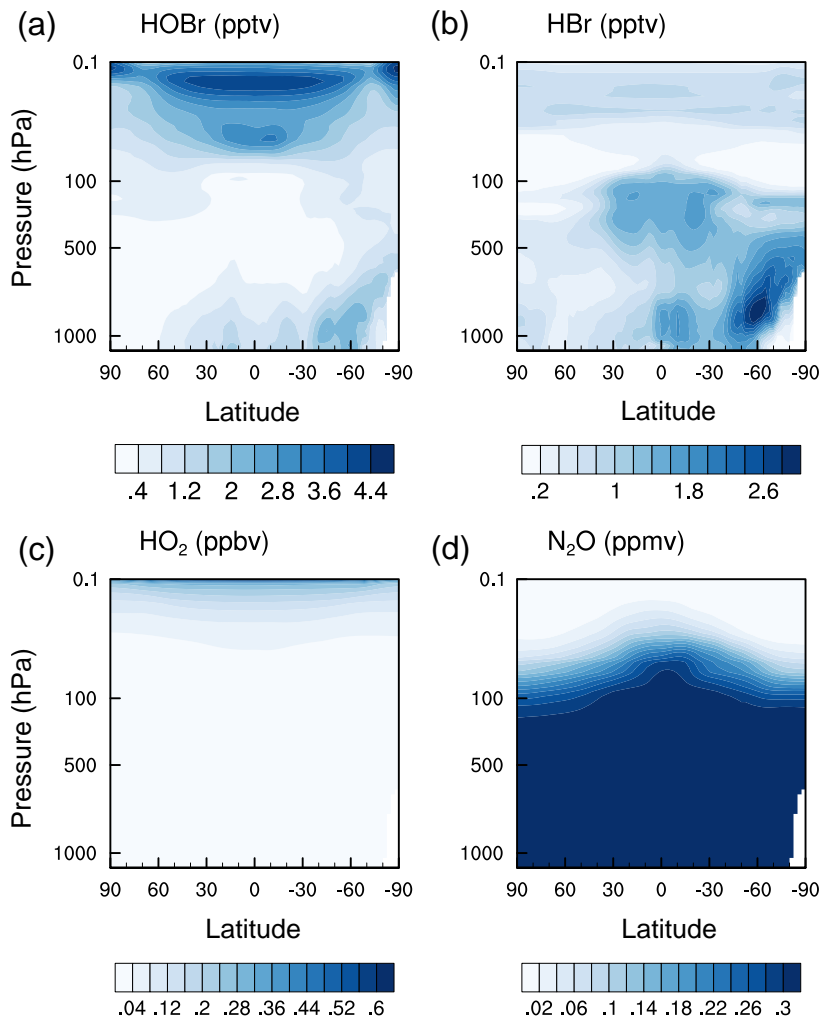

Figure 5. Zonal mean vertical concentrations for (a) $\mathrm{HOBr}$, (b) $\mathrm{HBr}$, (c) $\mathrm{HO}_{2}$ and (d) $\mathrm{N}_{2} \mathrm{O}$ produced by the stratospheric configuration of the UM-UKCA and interpolated to a fixed pressure grid. Data shown are the 2012 annual average. Note the different label bars and units.

timate of the variability of the species when divided into the six scenarios described in the previous section.

Additional gas climatologies are obtained from the Monitoring Atmospheric Composition and Climate (MACC) reanalysis data set (Inness et al., 2013). The MACC reanalysis data are produced with the Global and Regional Earth System Monitoring Using Satellite and in situ data (GEMS) Integrated Forecast System (IFS cycle 36r1) model at ECMWF and have the same spatial and temporal resolution as ERAInterim. MACC includes fields for $\mathrm{CO}_{2}, \mathrm{CO}, \mathrm{H}_{2} \mathrm{CO}$ and $\mathrm{SO}_{2}$ and has been validated against multiple sources of groundbased measurements and satellite data (Inness et al., 2013).
As with the UKCA profiles, all scenarios are derived from a complete 2012 data set. Profiles for remaining species with significant submillimetre lines are obtained from the Air Force Geophysics Lab (AFGL) Atmospheric Constituent Profiles (Anderson et al., 1986). These are single globally averaged profiles from 0 to $120 \mathrm{~km}$ that are appropriate for US standard conditions (NOAA, 1976) and are derived from a variety of sources including global satellite measurements and models. In general, AFGL adopts daytime estimates for diurnally varying species.

\subsection{Simulated downwelling observations}

The Atmospheric Radiative Transfer Simulator (ARTS) (version 2.2.41) available at http://www.radiativetransfer.org/ is the forward model used in this study (Buehler et al., 2005; Eriksson et al., 2011). ARTS is a monochromatic line-byline model that can simulate radiances from the infrared to the microwave and has been validated against other models in the submillimetre spectral range (Melsheimer et al., 2005). It includes contributions from spectral lines and continua via a choice of user-specified parameterisations. For this study, we use the Kuntz approximation to the Voigt lineshape (Kuntz, 1997) with a Van Vleck-Huber prefactor (Van Vleck and Huber, 1977), which is valid for all pressures considered and a line cut-off of $750 \mathrm{GHz}$. We use the Planck formalism for calculating brightness temperatures and spectroscopic line parameters are taken from the high-resolution transmission (HITRAN) molecular absorption database 2012 (Rothman et al., 2013). Other spectroscopic databases available include the JPL molecular line catalogue, which was designed specifically for millimetre/submillimetre astronomical applications (Pickett et al., 1998). However, the JPL catalogue does not include any pressure-broadening parameters, which are vital when considering line overlap effects in the atmospheric spectrum. Preliminary investigations show that root mean square intensity differences between the two databases at corresponding lines for $\mathrm{HBr}, \mathrm{HO}_{2}$ and $\mathrm{N}_{2} \mathrm{O}$ are within $4 \%$ for the $10 \%$ highest line intensities in the submillimetre range. The error in the conversion between JPL and HITRAN line intensities is within $2 \%$. The HOBr line intensities show far greater mean differences, of the order $71 \%$, because unlike the JPL catalogue, HITRAN does not resolve the hyperfine structure resulting from the intramolec- 
ular electromagnetic interactions of the nuclei with non-zero spins (Koga et al., 1989). Each hyperfine group in the JPL line list is composed of four very close transitions at frequencies within a $1-6 \mathrm{MHz}$ range, with the sum of the component intensities agreeing with HITRAN to within $4 \%$. As we use the HITRAN representation of these single, rather than split, $\mathrm{HOBr}$ lines this will potentially impact the radiative transfer calculations by overestimating signal strengths. It should also be noted that HITRAN does not include the $\mathrm{N}_{2} \mathrm{O}$ lines between $1357-15456 \mathrm{GHz}$, included in the JPL database.

The water vapour continuum parameterisation used is the most recent version of the Mlawer-Tobin CloughKneizys-Davies (MT-CKD) model (version 2.5.2), which separately includes both foreign and self-broadening components (Mlawer et al., 2012). Other possible choices investigated are an earlier version of the MT-CKD model (version 1.0) (Clough et al., 2005), which does not include more recent adjustments to the continuum coefficients based on observation fitting, and an even earlier formulation, CKD (version 2.4) (Tobin et al., 1999), based on Clough et al., 1989, which does not include collision-induced modifications. The Ma and Tipping (2002) model is the only fully theoretical model included, which is formulated from first quantum mechanical principles without fitting parameters to experimental data. Additionally, we test the Millimeter wave Propagation Model (MPM93) (Liebe et al., 1993) which includes both self and foreign continua and is commonly used for simulating the water vapour continuum at lower frequencies and the Rosenkranz (1998) model which combines the self-broadening component from MPM93 and the foreign component from the earlier Liebe (1989) formulation. Collision-induced absorption (CIA) is the main contribution to the dry continua in the submillimetre, hence for $\mathrm{N}_{2}, \mathrm{O}_{2}$ and $\mathrm{CO}_{2}$ the CIA parameterisation from the MT-CKD model (version 2.5.2) (Clough et al., 2005) is applied. All simulations are performed for a single pencil beam of radiation at a zenith angle of $0^{\circ}$, which is defined as looking straight up from the ground. The radiative transfer calculation is performed on a pressure altitude grid of up to 60 fixed pressure levels from $0.1 \mathrm{hPa}$ to the surface value.

\section{Estimation of receiver characteristics}

To measure a species signal it must be sufficiently distinguishable from the underlying atmospheric spectrum and errors sources within the receiver must be adequately accounted for. For example, standing waves in optical systems, are a central consideration when designing submillimetrewave spectrometers. These are well known to be problematic in both bolometric and coherent spectrometers. This is usually dealt with by ensuring optical system designs that minimise the effect, but also by fitting baselines. For narrow spectral lines, this is possible, but for broad spectral lines this can be a problem. In this study we only consider background noise, which arises due to the inherent natural variation of the
Table 4. Receiver noise temperatures for ALMA bands. Bands 3-10 are taken from Table 4.1 of Remijan (2015) and show the $T_{\text {rcr }}$ for any frequency in the range (the upper limit). Band 11 specifications are based on preparatory work by Masao Saito (Rigopoulou et al., 2013).

\begin{tabular}{lrr}
\hline Band & $\begin{array}{r}\text { Frequency range } \\
(\mathrm{GHz})\end{array}$ & $\begin{array}{r}T_{\text {rcr }} \\
(\mathrm{K})\end{array}$ \\
\hline 3 & $84.0-116.0$ & $<45$ \\
4 & $125.0-163.0$ & $<82$ \\
6 & $211.0-275.0$ & $<136$ \\
7 & $275.0-373.0$ & $<219$ \\
8 & $385.0-500.0$ & $<292$ \\
9 & $602.0-720.0$ & $<261$ \\
10 & $787.0-950.0$ & $<344$ \\
$11 \mathrm{a}$ & $1000.0-1300.0$ & $\sim 500$ \\
$11 \mathrm{~b}$ & $1300.0-1600.0$ & $\sim 4000$ \\
\hline
\end{tabular}

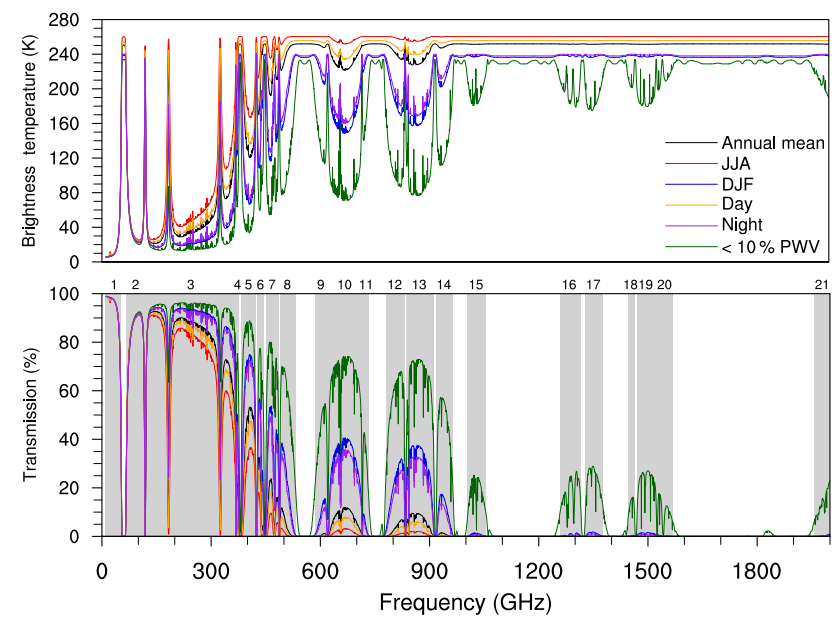

Figure 6. Downwelling brightness temperatures (top) and transmission (bottom) simulated by ARTS for the six scenarios, as viewed from the ground at Summit, Greenland (zenith angle $=0^{\circ}$ ). Full and partial window bands (consecutive frequencies with high transmission relative to those surrounding them) are shaded in grey on the lower panel and numbered above. The sampling resolution is $0.5 \mathrm{GHz}$.

flux of photons arriving at the receiver (Benford et al., 1998). This sets the limit of detectability with which to set technical specifications for any instruments built. The statistical fluctuation $\Delta T(\mathrm{~K})$ in the total system temperature $T_{\text {sys }}(\mathrm{K})$ is described by the ideal radiometer equation (Kraus, 1966):

$\Delta T=\frac{T_{\mathrm{sys}}}{\sqrt{\Delta \nu \tau}}$,

where $\Delta v$ is the signal bandwidth $(\mathrm{Hz}), \tau$ is the integration time (s) and we define $T_{\text {sys }}(\mathrm{K})$ as follows:

$T_{\text {sys }}=T_{\text {atm }}+T_{\text {sig }}+T_{\text {rcr }}$, 
where $T_{\text {atm }}$ is the atmospheric brightness temperature of the underlying atmosphere $(\mathrm{K}), T_{\text {sig }}$ is the signal strength $(\mathrm{K})$ and $T_{\text {rcr }}$ is the receiver noise temperature $(\mathrm{K})$. The signal-to-noise ratio $\left(T_{\text {sig }} / \Delta T\right)$ is set to 2 . This results in the following relationship between the $T_{\text {rcr }}$ and $\tau$ for a particular signal:

$T_{\text {rcr }}=T_{\text {sig }}\left(\frac{\sqrt{\Delta \nu \tau}}{2}-1\right)-T_{\text {atm }}$

The value of $T_{\text {rcr }}$ defines a minimum possible integration time. If instead the maximum integration time is set, this specifies a maximum receiver temperature which can be used to direct instrument design. The present study produces estimates of both quantities. To assess the minimum integration times that could be achieved, estimates of system noise temperatures for the various frequency bands are based on the front-end characteristics of the ALMA telescope receivers (Remijan, 2015), listed in Table 4. It should be noted that ALMA is a heterodyne system which represents the current state of the art in receiver technology; however, in principle smaller $T_{\text {rcr }}$ will be possible with future developments. For the inverse situation, we specify a typical integration time of $30 \mathrm{~min}$, chosen because this is a typical timescale of atmospheric processes and matches the minimum time step of many atmospheric models. This is additionally the time taken for a typical radiosonde ascent, which is advantageous when designing missions that require concurrent characterisation of the atmospheric state. If the bandwidth chosen encompasses the full frequency extent of the signal, the measurement will produce the total integrated radiance without resolving the finer features. This result could be appropriate if the total column abundance of a species is required. However, if a stratified vertical profile is the desired outcome the bandwidth needs to be split into a number of channels to characterise the height-dependent pressure-broadened line profile of the gas, which in turn will alter the dependant variables $T_{\text {rcr }}$ and $\tau$ in Eq. (3). For consistency across all cases, the bandwidth in this study is set to the full width at half maximum (FWHM) of the peak signal arising from the gas of interest.

\section{Atmospheric simulations}

\subsection{Background atmosphere}

Simulated downwelling spectra over the whole 10$2000 \mathrm{GHz}$ range for the background atmosphere are shown in Fig. 6 for all six scenarios at Summit, Greenland. For the benefit of both the atmospheric and astronomical communities, brightness temperature and transmission (from the top of the atmosphere to the surface) are shown in the upper and lower panels respectively. Frequency bands identified as atmospheric windows are shown in grey in the lower panel, with the condition that transmission falls to below $10 \%$ to define boundaries. The spectral features of both brightness temperature and transmission are essentially mirror images of each

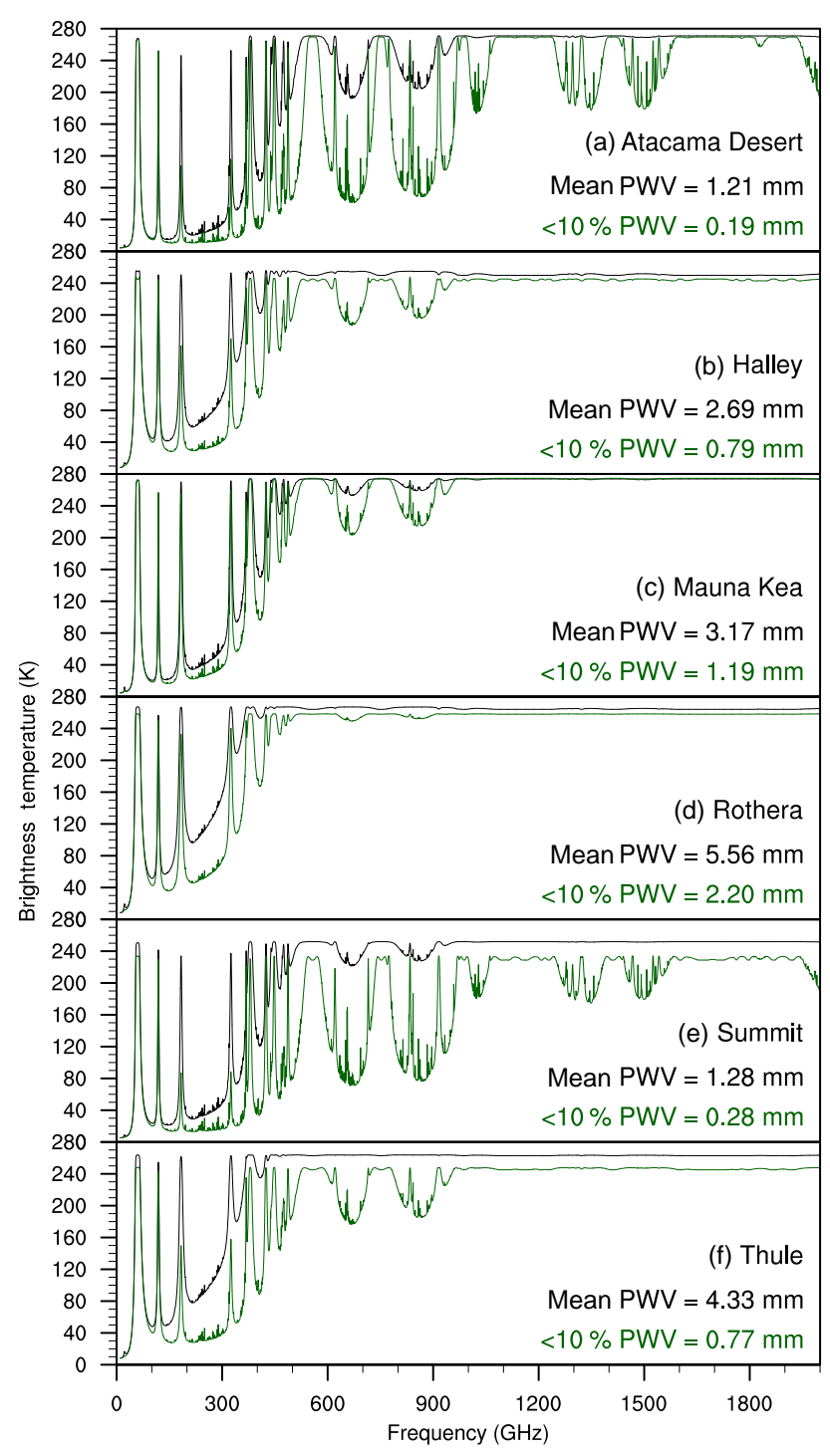

Figure 7. Simulated downwelling brightness temperatures as viewed from the ground for all six locations (a-f) Zenith angle $=0^{\circ}$. The two scenarios shown are the annual mean (black curve) and the $10 \%$ driest profiles (green curve). The mean and the lower dectile PWV are shown for each site.

other so only the former is used in the remainder of this study. Below $300 \mathrm{GHz}$ in the microwave region, windows are present that are relatively invariant to scenario; however at higher frequencies transmission is strongly dependent on atmospheric conditions. The scenarios with the driest conditions at Summit $<10 \% \mathrm{PWV}$, night and DJF, allow windows to open at higher frequencies. Above $1000 \mathrm{GHz}$ the atmosphere is almost totally opaque due to water vapour absorption and the brightness temperature approximates the equivalent blackbody temperature immediately above ground level.

Prominent features include the strong oxygen absorption bands around 60 and $120 \mathrm{GHz}$, water vapour bands at 183 , 325 and $380 \mathrm{GHz}$ and the fine structure within windows 


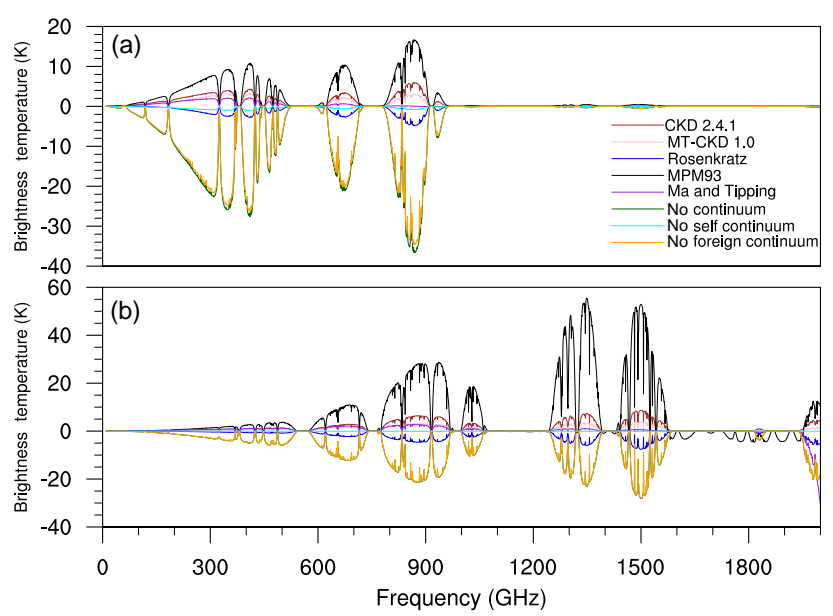

Figure 8. Spectral residuals between the downwelling brightness temperatures simulated with various continuum parameterisations available in ARTS and the configuration used throughout this study (MT-CKD 2.5.2) for (a) annual mean and (b) $<10 \%$ PWV scenarios at Summit, Greenland. Zenith angle $=0^{\circ}$.

which is predominately due to ozone. The JJA and daytime scenarios produce similar results because Northern Hemisphere polar locations experience perpetual sunlight in the boreal summer, so essentially JJA is the extreme of the daylight scenario. The same is true for DJF of the night-time scenario. For the Antarctic locations this pairing is switched as there is perpetual sunlight in DJF (austral summer) and perpetual night in JJA (austral winter). This pairing is not necessarily reproduced in the corresponding behaviour of trace gases, however. Figure 7 compares equivalent spectra at all six locations for the driest scenarios and the annual mean to show what could be achieved given favourable conditions that might be experienced for about 6 weeks of the year, reasonable for a well-timed campaign and more typical behaviour across all times. The Atacama desert and Summit show a similar opening of partial windows at high frequencies, above $1000 \mathrm{GHz}$, by virtue of their high elevations, even though temperature conditions and seasonal variability are very different at the two locations. Similarly, the spectra at Halley, Antarctica and Thule, Greenland are similar even though they are situated at opposite ends of the globe, as they are both coastal polar locations with similar climatologies.

\section{Water vapour continuum}

The effect of continuum parameterisation on the downwelling radiation is shown in Fig. 8 for both a higher- and a lower-humidity case at Summit. Contributions are largest in the atmospheric windows away from regions densely populated with water vapour lines. As the ambient humidity decreases more windows are available but the contribution in each is reduced in proportion with the lower water vapour concentration. In its entirety, the continuum contributes up to
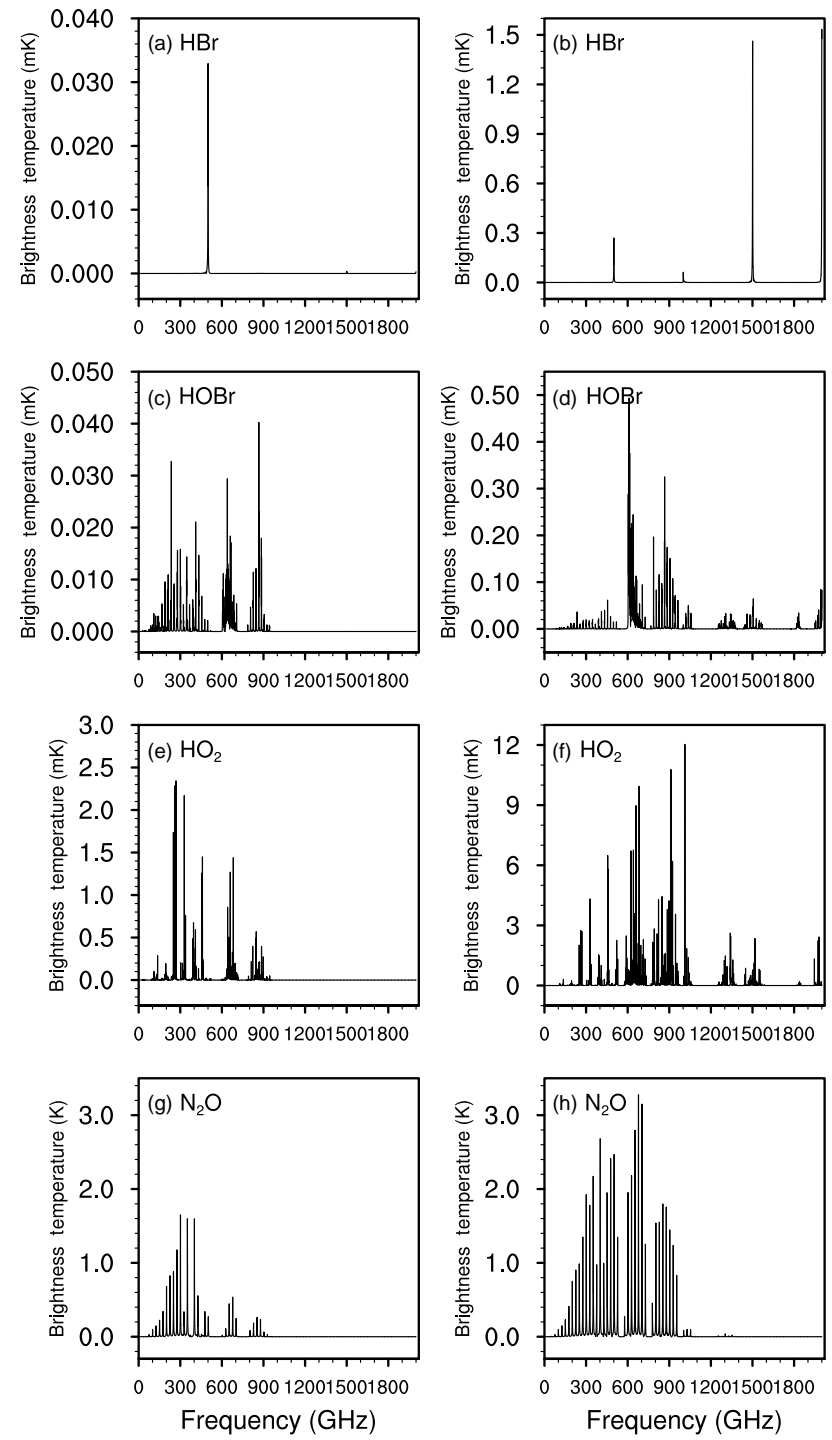

Figure 9. Total frequency range surveys of signal strength for the four species of interest at Summit (zenith angle $=0^{\circ}$ ) calculated as residual brightness temperatures between simulations of the complete atmosphere with and without the species $(0.5 \mathrm{GHz}$ sampling resolution). The plots on the left-hand side (a, $\mathbf{c}, \mathbf{e}$ and $\mathbf{g})$ are for the annual mean scenario and those on the right-hand side $(\mathbf{b}, \mathbf{d}, \mathbf{f}$ and h) are for the $<10 \%$ PWV scenario. Units of the ordinate scale are milliKelvin (mK) except for the $\mathrm{N}_{2} \mathrm{O}$ plots which are in $\mathrm{K}$. Note the different ordinate scales for each panel.

$40 \mathrm{~K}$ to the brightness temperature for the two cases shown (green line), which is far greater than the signals of all trace gases considered. Its fractional contribution to the total downwelling signal is up to $60 \%$ (in radiance units) in this region compared with those at higher frequencies, as the overall energy is low and the continuum contribution is inversely proportional to frequency. The continuum is almost totally dominated by the foreign component (orange line) in the submillimetre which is not necessarily the case in other 

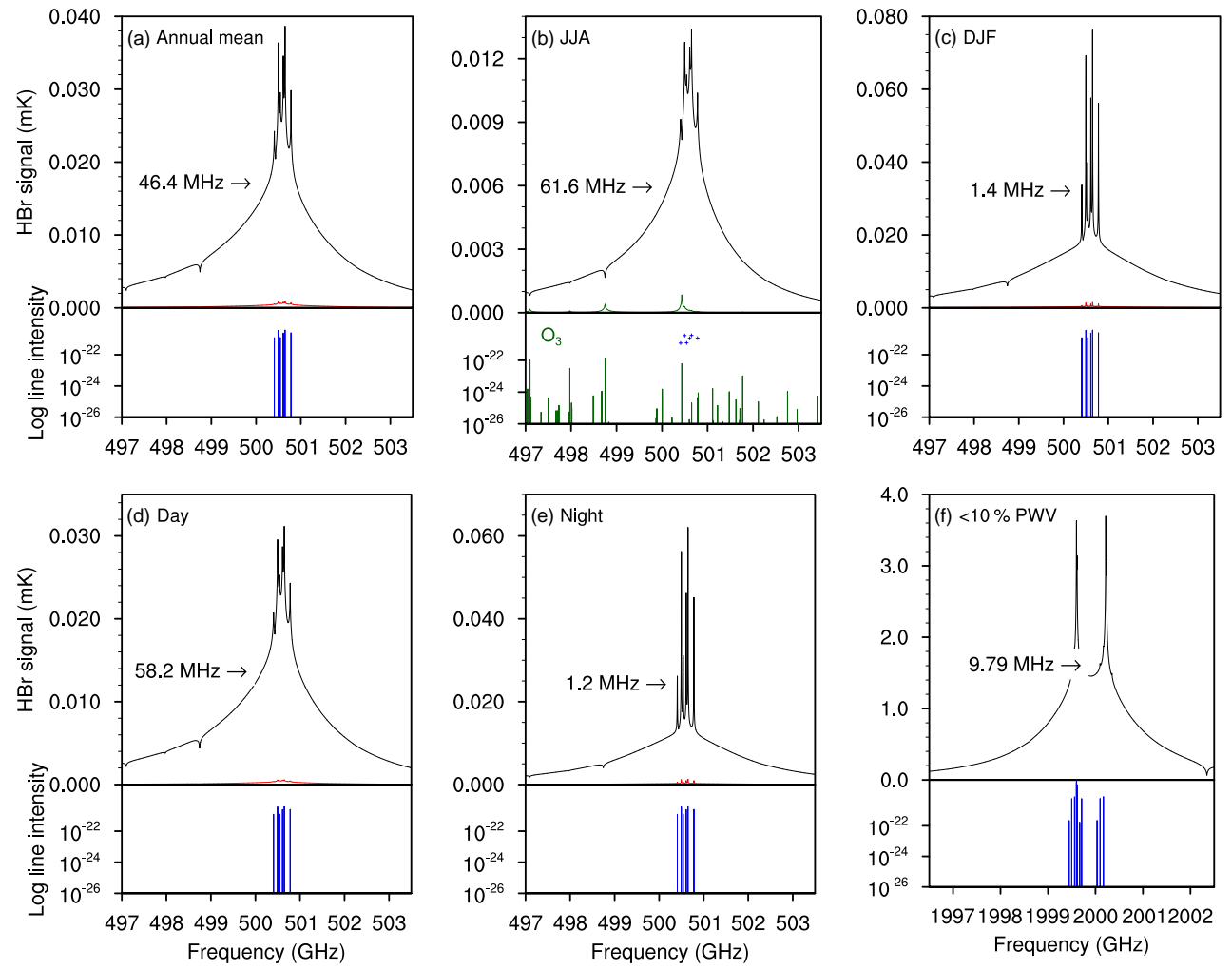

Figure 10. The spectrally enhanced $\mathrm{HBr}$ signal (1 MHz sampling resolution) around the strongest signal in each scenario (a-f) at Summit, calculated as a residual between simulations with and without $\mathrm{HBr}$. Red lines show the differences that result from using the Ma and Tipping water vapour continuum model. Arrows point to the position of the FWHM of the peak signal in each plot, labelled with the corresponding bandwidth. Units of the ordinate scale are $\mathrm{mK}$. The lower panels in each scenario show $\mathrm{HBr}$ intensities taken from the HITRAN database with $\log _{10}$ units of $\mathrm{cm}^{2}$ (molecules $\mathrm{cm}^{-2}$ ). The green line in the top panel of (b) shows the differences that result from doubling the vertical column of ozone concentrations at pressures $<200 \mathrm{hPa}$ to simulate a stratospheric increase. The lower panel of (b) presents the ozone line intensities with $\mathrm{HBr}$ lines reduced to scatter points for clarity.

regions, for example in the mid-infrared the self-continuum component contributes more than the foreign component.

It is clear from Fig. 8 that the choice of continuum model implemented in ARTS has a significant effect on the absolute brightness temperature. For example, the MPM93 model is used extensively when calculating atmospheric radiative transfer at frequencies below $300 \mathrm{GHz}$; however radiance differences between this and the MT-CKD 2.5.2 model can reach up to $20 \%$ at frequencies around $1000 \mathrm{GHz}$. Both CKD 2.4.1 and MT-CKD 1.0 are part of the same family as the control model MT-CKD 2.5.2, hence show its evolution over time. The MPM93 and Rosenkratz models were developed separately to the MT-CKD family, where the latter is based on parts of the former to provide better agreement with observations. Modifications between successive models are the result of mainly tuning coefficients to fit observations in measured frequency bands, which are then extrapolated to poorly understood regions like the submillimetre. Interestingly, the Ma and Tipping parameterisation, which is the only model to calculate the continuum from first principles without fitting to observations, produces results that are closest to the re- cently developed semi-empirical MT-CKD 2.5.2 model. The range of values obtained based on this handful of models gives an estimate of the uncertainty in this component of the simulation, which is known to dominate other errors such as the treatment of lines or other parts of the calculation. As continuum models are designed for certain frequency regimes it is important to select carefully depending on their strengths and be aware that none of the models considered are well validated in the submillimetre regime, particularly above $1000 \mathrm{GHz}$ (Buehler et al., 1996).

\subsection{Signals of $\mathrm{HBr}, \mathrm{HOBr}, \mathrm{HO}_{2}$ and $\mathrm{N}_{2} \mathrm{O}$}

Signal strengths over a broad frequency range are calculated as described in Sect. 3 for all species, scenarios and locations, a subset of which are shown in Fig. 9 for two scenarios at Summit. There is high variability between species, in terms of number and intensity of lines available, and between scenarios within a single species. Though Summit is a very dry transmissive location, $\mathrm{HOBr}$ produces a very small change in brightness temperature, below $0.5 \mathrm{mK}$ in every 

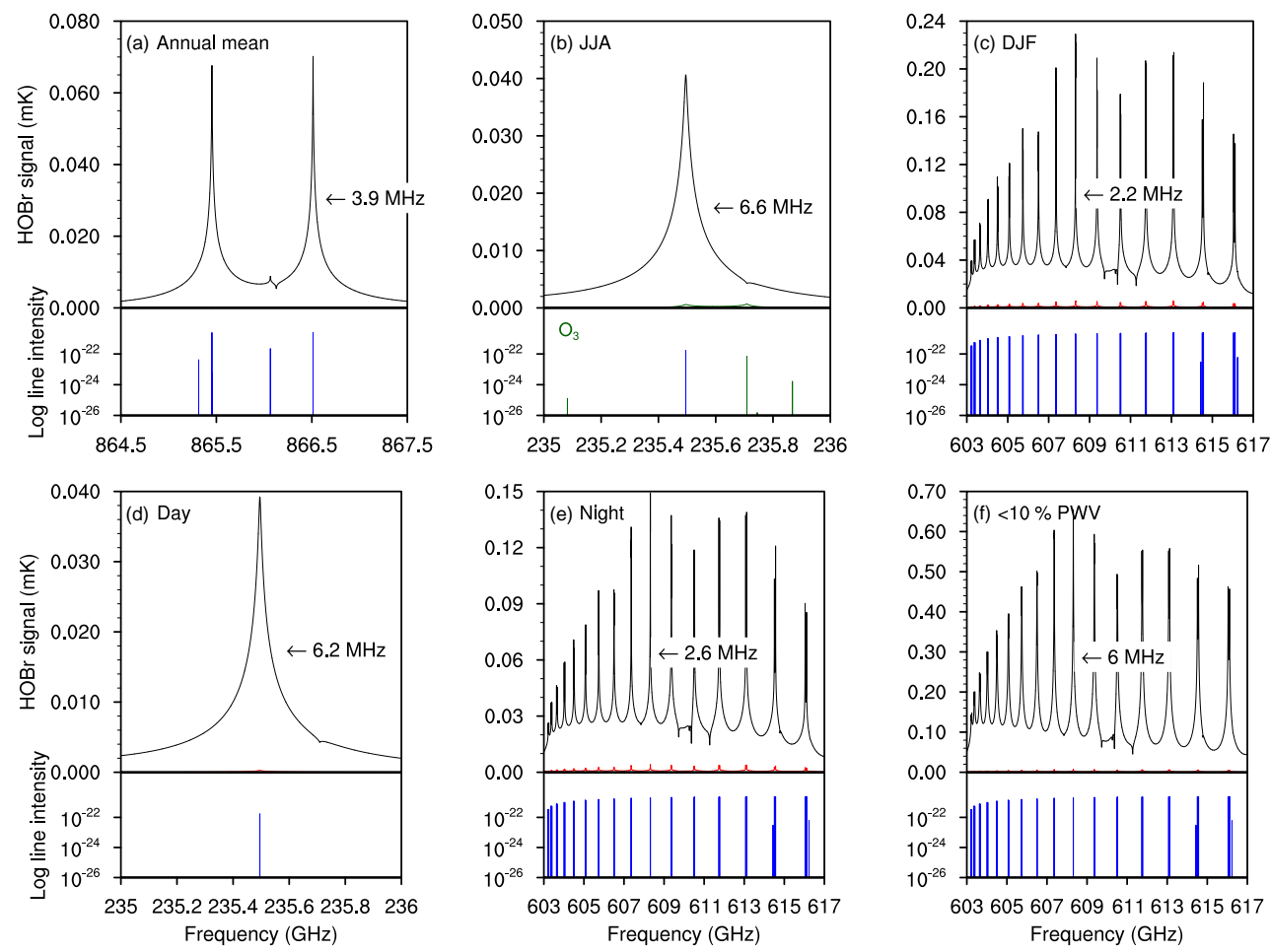

Figure 11. Same as Fig. 10 but for $\mathrm{HOBr}$.
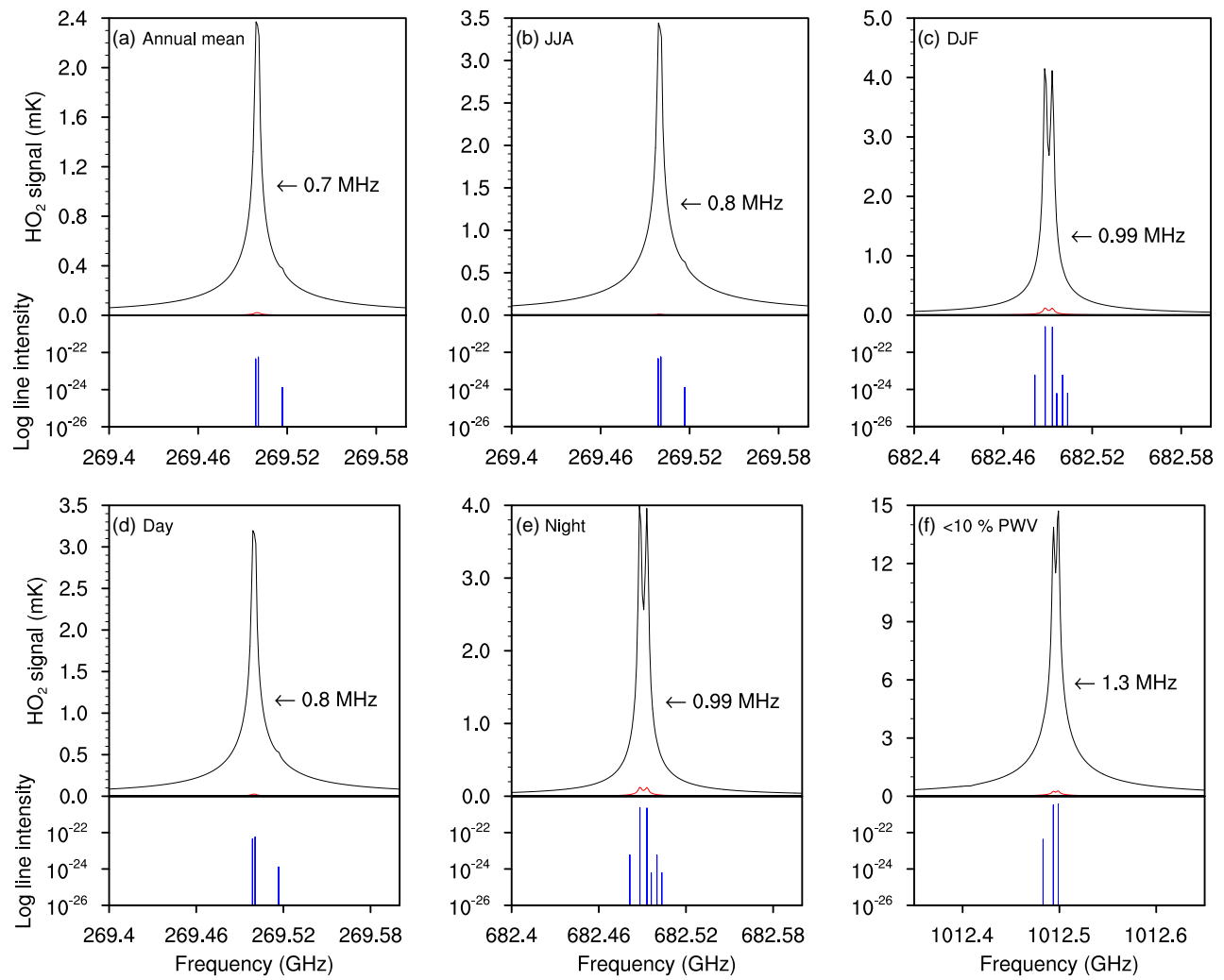

Figure 12. Same as Fig. 10 but for $\mathrm{HO}_{2}$. 

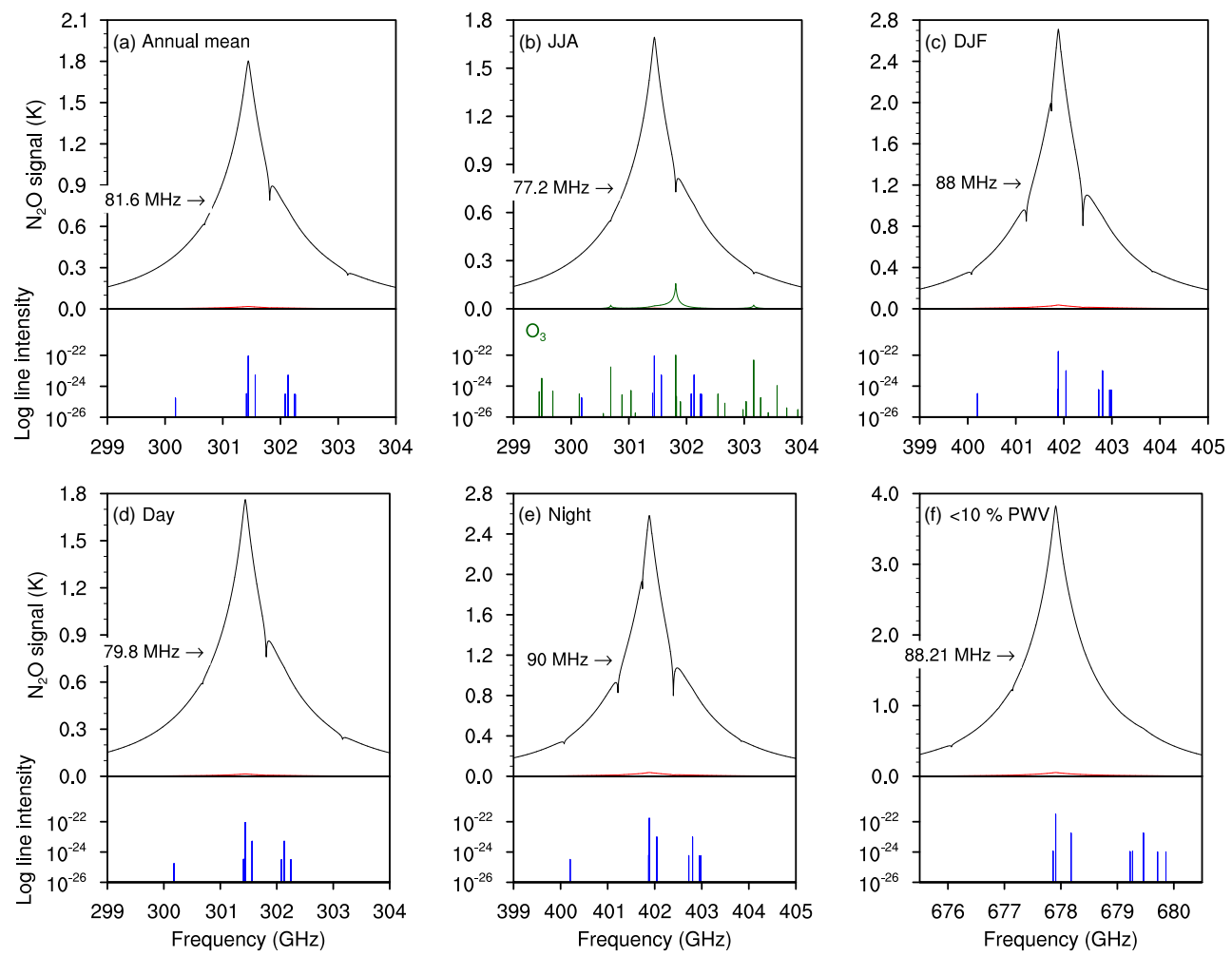

Figure 13. Same as Fig. 10 but for $\mathrm{N}_{2} \mathrm{O}$. Units of the ordinate scale are K.

scenario. $\mathrm{HBr}$ has sparse lines in the atmospheric window regions with a maximum brightness temperature change of $1.5 \mathrm{mK}$ under very dry conditions. $\mathrm{HO}_{2}$ shows signals that are at least an order of magnitude higher and the strongest $\mathrm{N}_{2} \mathrm{O}$ lines have peak brightness temperature above $1 \mathrm{~K}$ in all conditions. All species show a marked shift in signal distribution as conditions become dryer and more windows open up to reveal stronger lines at higher frequencies, hence the strongest line in the annual mean scenario is in nearly all cases different to the strongest line in the low PWV scenario. For example, in Fig. 9b HBr has a single prominent signal at around $500 \mathrm{GHz}$; however, in low-humidity conditions two lines emerge at 1500 and $2000 \mathrm{GHz}$ (Fig. 9f) that are about 50 times brighter. Small negative values at some frequencies are the result of increased absorption by neighbouring lines from other species, such as ozone, when the target species is removed.

Enhanced resolution simulations are performed in the vicinity of the strongest lines in each scenario and the corresponding measurement requirements are calculated. The results for each gas are shown for Summit in Figs. 10,11, 12 and 13 and results for all locations are listed in Tables 5, 6, 7 and 8. All panels show the full frequency extent of the strongest signal until it falls below $10 \%$ of the peak residual brightness temperature, which in many cases encompasses further peaks of lower intensity. As a guide, the position and intensity of transitions in the HITRAN database are shown in the panels below each signal. Red lines show the differences in brightness temperatures that result from using the Ma and Tipping parameterisation of the water vapour continuum instead of the MT-CKD 2.5.2. These appear to be minimal in all cases.

For $\mathrm{HBr}$ the peak centred at $500.648 \mathrm{GHz}$ is the brightest for all but the driest scenarios, where a stronger double peak emerges at $1999.8 \mathrm{GHz}$ and $2000.22 \mathrm{GHz}$ (Fig. 10). The $500.648 \mathrm{GHz}$ emission is composed of six component lines which are resolved close to the centre of the peak where narrowband emission by stratospheric $\mathrm{HBr}$ dominates. As previously noted, selecting the bandwidth is non-trivial as information about the gas at different heights is contained in different parts of the signal. For example, $\mathrm{HBr}$ volume mixing ratio reaches a maximum in the lower troposphere, decreases with height and then increases sharply in the stratosphere. The tropospheric contribution is manifested in the pressure-broadened wings of each emission line, and the stratospheric contribution emerges as the narrow spikes close to the line centre frequency. Depending on the bandwidth chosen, either within a single spike or encompassing the full width of the pressure broadened line, different vertical profile information can be retrieved from the measurement. In the DJF and night-time scenarios, the narrow $\mathrm{HBr}$ peak arises from the higher stratospheric signal under low water vapour conditions, whereas the results for JJA and daytime show greater contributions from the troposphere, with a 
Table 5. Characteristics of bands selected based on the strongest signal at each location and scenario for HBr. Minimum integration times, $\tau$, and maximum receiver noise temperatures, $T_{\mathrm{rcr}}$, are calculated from Eq. (3). The $T_{\mathrm{rcr}}$ used to calculate $\tau$ is given by the appropriate ALMA band in Table 4). $\tau$ is specified as $30 \mathrm{~min}$ when calculating $T_{\text {rcr }}$. The signal-to-noise ratio is 2 . A dash indicates that the signal is below this threshold.

\begin{tabular}{|c|c|c|c|c|c|c|c|}
\hline Location & Scenario & $\begin{array}{r}\text { Central } \\
\text { frequency } \\
(\mathrm{GHz})\end{array}$ & $\begin{array}{r}\text { Atmospheric } \\
\text { brightness } \\
\text { temperature } \\
(\mathrm{K})\end{array}$ & $\begin{array}{r}\text { Signal } \\
\text { strength } \\
(\mathrm{mK})\end{array}$ & Bandwidth & $\begin{array}{l}\text { Minimum } \\
\text { integration } \\
\text { time } \\
\text { (s) }\end{array}$ & $\begin{array}{r}\text { Maximum } \\
\text { receiver noise } \\
\text { temperature } \\
(\mathrm{K})\end{array}$ \\
\hline \multirow[t]{6}{*}{ Summit } & all & 500.65 & 229.6 & 0.0387 & 46.402 & $1.549 \mathrm{E}+07$ & - \\
\hline & JJA & 500.65 & 255.1 & 0.0134 & 61.600 & $1.083 \mathrm{E}+08$ & - \\
\hline & DJF & 500.65 & 162.0 & 0.0762 & 1.404 & $1.011 \mathrm{E}+08$ & - \\
\hline & day & 500.65 & 240.4 & 0.0311 & 58.200 & $2.006 \mathrm{E}+08$ & - \\
\hline & night & 500.65 & 173.1 & 0.0621 & 1.202 & $1.878 \mathrm{E}+09$ & - \\
\hline & $<10 \% \mathrm{PWV}$ & 2000.22 & 186.2 & 3.6961 & 9.790 & $5.241 \mathrm{E}+06$ & 59.166 \\
\hline \multirow[t]{6}{*}{ Halley } & all & 500.65 & 254.8 & 0.0025 & 219.397 & $8.863 \mathrm{E}+08$ & - \\
\hline & JJA & 500.65 & 244.4 & 0.0106 & 20.801 & $4.887 \mathrm{E}+08$ & - \\
\hline & DJF & 500.65 & 266.5 & 0.0004 & 223.996 & $4.547 \mathrm{E}+10$ & - \\
\hline & day & 500.65 & 258.5 & 0.0011 & 239.001 & $4.514 \mathrm{E}+09$ & - \\
\hline & night & 500.65 & 248.0 & 0.0050 & 2.600 & $1.809 \mathrm{E}+10$ & - \\
\hline & $<10 \% \mathrm{PWV}$ & 500.65 & 200.2 & 0.2090 & 199.200 & $1.114 \mathrm{E}+05$ & - \\
\hline \multirow[t]{4}{*}{ Atacama } & all & 500.65 & 204.1 & 0.2505 & 112.802 & $1.391 \mathrm{E}+05$ & - \\
\hline & JJA & 500.65 & 166.3 & 0.4281 & 132.999 & $3.447 \mathrm{E}+04$ & - \\
\hline & DJF & 500.65 & 180.8 & 0.2653 & 73.599 & $1.726 \mathrm{E}+05$ & - \\
\hline & $<10 \% \mathrm{PWV}$ & 2000.2 & 181.9 & 10.7013 & 115.198 & $5.303 \mathrm{E}+03$ & 2254.614 \\
\hline \multirow[t]{4}{*}{ Mauna Kea } & all & 500.65 & 259.1 & 0.0602 & 123.599 & $2.711 \mathrm{E}+06$ & - \\
\hline & JJA & 500.65 & 256.4 & 0.0752 & 112.201 & $1.716 \mathrm{E}+06$ & - \\
\hline & DJF & 500.65 & 255.6 & 0.0752 & 137.799 & $1.537 \mathrm{E}+06$ & - \\
\hline & $<10 \% \mathrm{PWV}$ & 500.65 & 202.9 & 0.3290 & 121.201 & $7.470 \mathrm{E}+04$ & - \\
\hline \multirow[t]{6}{*}{ Rothera } & all & 254.70 & 115.5 & $2.151 \mathrm{E}-05$ & 456.201 & $1.199 \mathrm{E}+12$ & - \\
\hline & JJA & 500.65 & 263.2 & $5.292 \mathrm{E}-05$ & 95.200 & $4.625 \mathrm{E}+12$ & - \\
\hline & DJF & 254.70 & - & - & - & - & - \\
\hline & day & 254.70 & - & - & - & - & - \\
\hline & night & 500.65 & 264.7 & $1.860 \mathrm{E}-05$ & 24.399 & $1.468 \mathrm{E}+14$ & - \\
\hline & $<10 \% \mathrm{PWV}$ & 500.65 & 252.9 & 0.0201 & 220.398 & $1.335 \mathrm{E}+07$ & - \\
\hline \multirow[t]{6}{*}{ Thule } & all & 500.65 & 263.7 & $7.061 \mathrm{E}-05$ & 89.401 & $2.771 \mathrm{E}+12$ & - \\
\hline & JJA & 254.70 & - & - & - & - & - \\
\hline & DJF & 500.65 & 236.0 & 0.0185 & 1.000 & $4.239 \mathrm{E}+09$ & - \\
\hline & day & 500.65 & 267.7 & $1.184 \mathrm{E}-05$ & 210.001 & $4.255 \mathrm{E}+13$ & - \\
\hline & night & 500.65 & 247.3 & 0.0057 & 1.202 & $3.021 \mathrm{E}+10$ & - \\
\hline & $<10 \% \mathrm{PWV}$ & 500.65 & 190.6 & 0.1100 & 48.999 & $1.570 \mathrm{E}+06$ & - \\
\hline
\end{tabular}

smaller signal corresponding to a wider bandwidth. In the $10 \%$ lowest-humidity case (Fig. 10f), the double peak is the envelope of nine components at $1999.9 \mathrm{GHz}$ and three at $2000.22 \mathrm{GHz}$. Interestingly, the more numerous and intense lines at $1999.9 \mathrm{GHz}$ do not produce as bright a peak as the latter because of the greater attenuation of the signal by water vapour at the lower frequency, as shown by Urban (2003), who calculates the $1999.9 \mathrm{GHz}$ signal to be the stronger of the two when viewed from a tangent altitude of $20 \mathrm{~km}$. This highlights the importance of performing the full radiative transfer simulation rather than inferring behaviour from catalogued line intensities or previous reports of signals observed from different locations or platforms.

$\mathrm{HOBr}$ is most abundant in the stratosphere (see Fig. 5a), hence produces narrow brightness temperature peaks with small, broader contributions from the tropospheric component (Fig. 11). It is has a strong diurnal cycle because it is photolysed by solar radiation, thus its volume mixing ratio increases during night-time, evidenced by the brighter signals in Fig. 11c, e and $\mathrm{f}$ (the latter because most low-humidity profiles will be produced at night). Without a mechanism to destroy it, $\mathrm{HOBr}$ will build up in the stratosphere and troposphere, leading to the enhanced signals and wider pressure- 
Table 6. As Table 5 but for $\mathrm{HOBr}$.

\begin{tabular}{|c|c|c|c|c|c|c|c|}
\hline Location & Scenario & $\begin{array}{r}\text { Central } \\
\text { frequency } \\
(\mathrm{GHz})\end{array}$ & $\begin{array}{r}\text { Atmospheric } \\
\text { brightness } \\
\text { temperature } \\
(\mathrm{K})\end{array}$ & $\begin{array}{r}\text { Signal } \\
\text { strength } \\
(\mathrm{mK})\end{array}$ & Bandwidth & $\begin{array}{l}\text { Minimum } \\
\text { integration } \\
\text { time } \\
\text { (s) }\end{array}$ & $\begin{array}{r}\text { Maximum } \\
\text { receiver noise } \\
\text { temperature } \\
(\mathrm{K})\end{array}$ \\
\hline \multirow[t]{6}{*}{ Summit } & all & 865.45 & 228.1 & 0.0676 & 3.998 & $7.161 \mathrm{E}+07$ & - \\
\hline & JJA & 235.50 & 45.0 & 0.0406 & 6.599 & $1.229 \mathrm{E}+07$ & - \\
\hline & DJF & 608.32 & 207.1 & 0.2292 & 2.203 & $7.573 \mathrm{E}+06$ & - \\
\hline & day & 235.50 & 38.6 & 0.0392 & 6.200 & $1.278 \mathrm{E}+07$ & - \\
\hline & night & 608.32 & 215.7 & 0.1491 & 2.600 & $1.569 \mathrm{E}+07$ & - \\
\hline & $<10 \% \mathrm{PWV}$ & 608.32 & 116.2 & 0.6547 & 6.000 & $2.213 \mathrm{E}+05$ & - \\
\hline \multirow[t]{6}{*}{ Halley } & all & 235.5 & 65.7 & 0.0450 & 5.400 & $1.490 \mathrm{E}+07$ & - \\
\hline & JJA & 235.50 & 46.2 & 0.0066 & 0.800 & $4.002 \mathrm{E}+07$ & - \\
\hline & DJF & 233.80 & 84.1 & 0.0374 & 8.600 & $1.612 \mathrm{E}+07$ & - \\
\hline & day & 233.80 & 74.8 & 0.0372 & 9.399 & $1.365 \mathrm{E}+07$ & - \\
\hline & night & 300.91 & 77.6 & 0.100 & 0.800 & $4.391 \mathrm{E}+07$ & - \\
\hline & $<10 \% \mathrm{PWV}$ & 865.45 & 196.4 & 0.204 & 6.397 & $4.371 \mathrm{E}+06$ & - \\
\hline \multirow[t]{4}{*}{ Atacama } & all & 866.51 & 204.9 & 0.1922 & 5.695 & $5.728 \mathrm{E}+06$ & - \\
\hline & JJA & 866.51 & 166.9 & 0.2917 & 5.908 & $2.078 \mathrm{E}+06$ & - \\
\hline & DJF & 866.51 & 182.6 & 0.2725 & 5.298 & $2.820 \mathrm{E}+06$ & - \\
\hline & $<10 \% \mathrm{PWV}$ & 608.31 & 101.7 & 0.8563 & 6.396 & $1.122 \mathrm{E}+05$ & - \\
\hline \multirow[t]{4}{*}{ Mauna Kea } & all & 235.50 & 39.4 & 0.0466 & 5.701 & $9.954 \mathrm{E}+06$ & - \\
\hline & JJA & 235.50 & 37.1 & 0.0488 & 5.701 & $8.826 \mathrm{E}+06$ & - \\
\hline & DJF & 235.50 & 37.8 & 0.0440 & 5.701 & $1.093 \mathrm{E}+07$ & - \\
\hline & $<10 \% \mathrm{PWV}$ & 866.54 & 203.1 & 0.2022 & 5.908 & $4.956 \mathrm{E}+06$ & - \\
\hline \multirow[t]{6}{*}{ Rothera } & all & 235.5 & 105.5 & 0.0360 & 5.400 & $3.325 \mathrm{E}+07$ & - \\
\hline & JJA & 235.50 & 86.7 & 0.0558 & 0.999 & $6.385 \mathrm{E}+07$ & - \\
\hline & DJF & 233.80 & 122.6 & 0.0292 & 8.400 & $3.731 \mathrm{E}+07$ & - \\
\hline & day & 233.80 & 109.9 & 0.0303 & 8.600 & $3.057 \mathrm{E}+07$ & - \\
\hline & night & 235.50 & 92.9 & 0.0483 & 1.399 & $6.435 \mathrm{E}+07$ & - \\
\hline & $<10 \% \mathrm{PWV}$ & 235.50 & 51.6 & 0.0485 & 5.800 & $1.031 \mathrm{E}+07$ & - \\
\hline \multirow[t]{6}{*}{ Thule } & all & 235.50 & 86.7 & 0.0444 & 1.099 & $9.154 \mathrm{E}+07$ & - \\
\hline & JJA & 235.50 & 136.8 & 0.0211 & 6.000 & $1.111 \mathrm{E}+07$ & - \\
\hline & DJF & 235.50 & 43.8 & 0.1088 & 0.500 & $2.185 \mathrm{E}+07$ & - \\
\hline & day & 235.50 & 101.6 & 0.0242 & 5.499 & $6.986 \mathrm{E}+07$ & - \\
\hline & night & 235.50 & 50.0 & 0.0799 & 0.500 & $4.325 \mathrm{E}+07$ & - \\
\hline & $<10 \% \mathrm{PWV}$ & 865.45 & 186.0 & 0.2713 & 1.099 & $1.389 \mathrm{E}+07$ & - \\
\hline
\end{tabular}

broadened lines seen in these three scenarios. Each of the peaks comprises two to three components; however, as detailed in the Sect. 3.3, each of these is a composite of the hyperfine structure not resolved in the HITRAN line list, thus the actual signal, spread over a wider frequency interval, could have a lower peak.

$\mathrm{HO}_{2}$ in the stratosphere and mesosphere will produce narrow peaks, with FWHM line widths in the range $\sim 100 \mathrm{kHz}-$ $1 \mathrm{MHz}$ (Fig. 12). The peak brightness temperatures that are calculated for the $\mathrm{HO}_{2}$ peaks are one to two orders of magnitude lower than those observed at $254.44 \mathrm{GHz}$ by the $\mathrm{Na}$ tional Radio Astronomy Observatory telescope at Kitt Peak, Arizona $\left(31^{\circ} \mathrm{N}, 110^{\circ} \mathrm{W}\right)$ by Clancy et al. (1994), which could be due to the combination of two factors. Firstly, the spectral resolution is set at $1 \mathrm{MHz}$ in the present simulations whereas a $250 \mathrm{kHz}$ resolution of the Kitt Peak observations would yield a sharper line with higher peak brightness temperature. Secondly, our input atmospheric profiles are averaged climatologies and $\mathrm{HO}_{2}$ has strong diurnal and seasonal variability and can be enhanced by orders of magnitude during energetic particle precipitation and atmospheric ionisation events associated with solar and geomagnetic storms. It is, therefore, quite possible that observed signals could often be higher than those simulated here.

A potential source of error when selecting the optimum signals for each species is the presence of overlapping lines from other gases close to the target peak frequency. This is particularly true if the concentrations of the interfering 
Table 7. As Table 5 but for $\mathrm{HO}_{2}$.

\begin{tabular}{|c|c|c|c|c|c|c|c|}
\hline Location & Scenario & $\begin{array}{r}\text { Central } \\
\text { frequency } \\
(\mathrm{GHz})\end{array}$ & $\begin{array}{r}\text { Atmospheric } \\
\text { brightness } \\
\text { temperature } \\
(\mathrm{K})\end{array}$ & $\begin{array}{r}\text { Signal } \\
\text { strength } \\
(\mathrm{mK})\end{array}$ & Bandwidth & $\begin{array}{l}\text { Minimum } \\
\text { integration } \\
\text { time } \\
\text { (s) }\end{array}$ & $\begin{array}{r}\text { Maximum } \\
\text { receiver noise } \\
\text { temperature } \\
(\mathrm{K})\end{array}$ \\
\hline \multirow[t]{6}{*}{ Summit } & all & 269.45 & 37.7 & 2.371 & 0.699 & $3.071 \mathrm{E}+04$ & 4.350 \\
\hline & JJA & 269.45 & 54.5 & 3.441 & 0.799 & $1.535 \mathrm{E}+04$ & 10.728 \\
\hline & DJF & 682.49 & 152.9 & 4.149 & 0.995 & $4.002 \mathrm{E}+04$ & - \\
\hline & day & 269.50 & 42.8 & 3.197 & 0.799 & $1.566 \mathrm{E}+04$ & 17.820 \\
\hline & night & 682.49 & 164.3 & 3.991 & 0.995 & $4.566 \mathrm{E}+04$ & - \\
\hline & $<10 \% \mathrm{PWV}$ & 1012.50 & 193.1 & 14.716 & 1.300 & $6.827 \mathrm{E}+03$ & 162.735 \\
\hline \multirow[t]{6}{*}{ Halley } & all & 260.57 & 72.1 & 8.969 & 0.400 & $5.386 \mathrm{E}+03$ & 48.175 \\
\hline & JJA & 269.50 & 55.9 & 0.463 & 0.598 & $1.149 \mathrm{E}+06$ & - \\
\hline & DJF & 260.57 & 99.8 & 12.852 & 0.400 & $3.368 \mathrm{E}+03$ & 72.583 \\
\hline & day & 269.50 & 87.1 & 2.697 & 0.800 & $3.421 \mathrm{E}+04$ & - \\
\hline & night & 269.50 & 59.7 & 0.476 & 0.598 & $1.130 \mathrm{E}+06$ & - \\
\hline & $<10 \% \mathrm{PWV}$ & 682.49 & 191.8 & 10.671 & 1.093 & $6.589 \mathrm{E}+03$ & 44.866 \\
\hline \multirow[t]{4}{*}{ Atacama } & all & 682.49 & 197.4 & 19.699 & 1.306 & $1.659 \mathrm{E}+03$ & 280.140 \\
\hline & JJA & 682.49 & 159.1 & 26.505 & 1.196 & $8.404 \mathrm{E}+02$ & 455.735 \\
\hline & DJF & 682.49 & 173.9 & 29.531 & 1.306 & $6.643 \mathrm{E}+02$ & 541.990 \\
\hline & $<10 \% \mathrm{PWV}$ & 1012.50 & 189.5 & 37.474 & 1.300 & $1.042 \mathrm{E}+03$ & 716.869 \\
\hline \multirow[t]{4}{*}{ Mauna Kea } & all & 260.57 & 43.6 & 18.843 & 0.400 & $9.088 \mathrm{E}+02$ & 209.159 \\
\hline & JJA & 260.57 & 40.8 & 20.538 & 0.400 & $7.413 \mathrm{E}+02$ & 234.697 \\
\hline & DJF & 260.57 & 41.7 & 17.291 & 0.501 & $8.442 \mathrm{E}+02$ & 217.788 \\
\hline & $<10 \% \mathrm{PWV}$ & 682.49 & 195.7 & 22.179 & 1.196 & $1.418 \mathrm{E}+03$ & 318.859 \\
\hline \multirow[t]{6}{*}{ Rothera } & all & 260.57 & 118.9 & 6.542 & 0.400 & $1.518 \mathrm{E}+04$ & - \\
\hline & JJA & 269.50 & 102.6 & 0.358 & 0.598 & $2.966 \mathrm{E}+06$ & - \\
\hline & DJF & 260.57 & 138.3 & 9.581 & 0.400 & $8.202 \mathrm{E}+03$ & - \\
\hline & day & 260.57 & 123.7 & 9.150 & 0.500 & $6.437 \mathrm{E}+03$ & 13.627 \\
\hline & night & 269.50 & 110.1 & 0.370 & 0.598 & $2.967 \mathrm{E}+06$ & - \\
\hline & $<10 \% \mathrm{PWV}$ & 260.57 & 54.9 & 9.372 & 0.500 & $3.315 \mathrm{E}+03$ & 85.768 \\
\hline \multirow[t]{6}{*}{ Thule } & all & 269.50 & 102.1 & 1.329 & 0.699 & $1.838 \mathrm{E}+05$ & - \\
\hline & JJA & 262.00 & 155.2 & 4.267 & 0.598 & $3.115 \mathrm{E}+04$ & - \\
\hline & DJF & 269.50 & 46.0 & 0.180 & 0.500 & $8.168 \mathrm{E}+06$ & - \\
\hline & day & 269.50 & 120.5 & 1.979 & 0.800 & $8.401 \mathrm{E}+04$ & - \\
\hline & night & 269.50 & 54.4 & 0.421 & 0.598 & $1.367 \mathrm{E}+06$ & - \\
\hline & $<10 \% \mathrm{PWV}$ & 682.49 & 180.9 & 9.872 & 1.093 & 7.337E+03 & 37.975 \\
\hline
\end{tabular}

species are higher than those estimated in the atmospheric profiles used in the radiative transfer calculations. The sensitivities of these strongest signals to changes in ozone concentration are tested, as this species has numerous lines in the submillimetre that can interfere with the target emission lines. We focus on the winter (JJA) scenario as a favourable season for campaigns in Greenland, due to cold, dry conditions producing low atmospheric opacity. The $13 \mu \mathrm{K} \mathrm{HBr}$ signal centred at $500.65 \mathrm{GHz}$ (Fig. 10b) is overlapped by the ${ }^{16} \mathrm{O}_{3}$ line at $500.43 \mathrm{GHz}$. Doubling stratospheric ozone concentrations, at atmospheric pressures below $200 \mathrm{hPa}$ reduces the peak $\mathrm{HBr}$ signal by $1 \mu \mathrm{K}$ (Fig. 10b), i.e. a change of $8 \%$ from the unperturbed calculation. Halving the $\mathrm{O}_{3}$ concentration produces no significant change in the peak $\mathrm{HBr}$ signal.
For $\mathrm{HOBr}$ there are no ozone lines in the signal bandwidth (Figures 11b) and for $\mathrm{HO}_{2}$ all overlapping $\mathrm{O}_{3}$ lines are weak with line intensities below $10^{-26} \mathrm{~cm}^{-1} /\left(\right.$ molecules $\mathrm{cm}^{-2}$ ) (Fig. 12b); therefore the target lines for these two molecules show negligible responses to changes in ozone concentration. The $\mathrm{N}_{2} \mathrm{O}$ transition centred at $301.44 \mathrm{GHz}$ (signal strength $=1.7 \mathrm{~K}$ ) is overlapped at the edge of the FWHM by a ${ }^{16} \mathrm{O}_{3}$ transition at $301.81 \mathrm{GHz}$ of similar intensity (Fig. 13b). Doubling the $\mathrm{O}_{3}$ concentration reduces the edge of the $\mathrm{N}_{2} \mathrm{O}$ signal by $0.15 \mathrm{~K}$ but has a negligible effect on the peak signal. Though the calculated sensitivities of these particular signals to $\mathrm{O}_{3}$ are minimal, they emphasise the need for accurate profiles of overlapping atmospheric species. Vertical $\mathrm{O}_{3}$ columns are well measured by satellites and ground 
Table 8. As Table 5 but for $\mathrm{N}_{2} \mathrm{O}$.

\begin{tabular}{|c|c|c|c|c|c|c|c|}
\hline Location & Scenario & $\begin{array}{r}\text { Central } \\
\text { frequency } \\
(\mathrm{GHz})\end{array}$ & $\begin{array}{r}\text { Atmospheric } \\
\text { brightness } \\
\text { temperature } \\
(\mathrm{K})\end{array}$ & $\begin{array}{r}\text { Signal } \\
\text { strength } \\
(\mathrm{K})\end{array}$ & Bandwidth & $\begin{array}{l}\text { Minimum } \\
\text { integration } \\
\text { time } \\
\text { (s) }\end{array}$ & $\begin{array}{r}\text { Maximum } \\
\text { receiver noise } \\
\text { temperature } \\
(\mathrm{K})\end{array}$ \\
\hline \multirow[t]{6}{*}{ Summit } & all & 301.44 & 52.9 & 1.804 & 81.598 & $1.129 \mathrm{E}-03$ & 292.745 \\
\hline & JJA & 301.44 & 77.2 & 1.693 & 77.203 & $1.583 \mathrm{E}-03$ & 240.327 \\
\hline & DJF & 401.88 & 80.6 & 2.712 & 88.004 & 8.703E-04 & 459.122 \\
\hline & day & 301.44 & 59.9 & 1.762 & 79.800 & $1.271 \mathrm{E}-03$ & 272.040 \\
\hline & night & 401.88 & 86.2 & 2.583 & 89.999 & $9.959 \mathrm{E}-04$ & 433.610 \\
\hline & $<10 \% \mathrm{PWV}$ & 677.91 & 75.2 & 3.828 & 88.208 & $3.578 \mathrm{E}-04$ & 687.453 \\
\hline \multirow[t]{6}{*}{ Halley } & all & 301.44 & 101.3 & 1.509 & 126.001 & $1.443 \mathrm{E}-03$ & 258.065 \\
\hline & JJA & 301.44 & 72.7 & 1.680 & 141.400 & $8.626 \mathrm{E}-04$ & 351.096 \\
\hline & DJF & 301.44 & 129.6 & 1.396 & 85.400 & $2.945 \mathrm{E}-03$ & 144.027 \\
\hline & day & 301.44 & 114.4 & 1.410 & 121.201 & $1.861 \mathrm{E}-03$ & 214.881 \\
\hline & night & 301.44 & 79.6 & 1.667 & 134.601 & $9.643 \mathrm{E}-04$ & 330.642 \\
\hline & $<10 \% \mathrm{PWV}$ & 401.88 & 107.8 & 2.505 & 110.199 & $9.362 \mathrm{E}-04$ & 450.041 \\
\hline \multirow[t]{4}{*}{ Atacama } & all & 401.88 & 102.1 & 3.439 & 45.599 & $1.172 \mathrm{E}-03$ & 390.594 \\
\hline & JJA & 401.88 & 80.0 & 7.781 & 48.001 & $1.985 \mathrm{E}-04$ & 1063.559 \\
\hline & DJF & 401.88 & 87.6 & 3.852 & 44.199 & $8.965 \mathrm{E}-04$ & 455.7191 \\
\hline & $<10 \% \mathrm{PWV}$ & 702.98 & 84.9 & 5.338 & 44.000 & $3.935 \mathrm{E}-04$ & 666.281 \\
\hline \multirow[t]{4}{*}{ Mauna Kea } & all & 301.44 & 65.1 & 2.325 & 50.201 & $1.905 \mathrm{E}-03$ & 284.288 \\
\hline & JJA & 301.44 & 61.1 & 2.403 & 49.200 & $1.780 \mathrm{E}-04$ & 296.392 \\
\hline & DJF & 301.44 & 62.3 & 2.291 & 52.997 & $1.827 \mathrm{E}-04$ & 291.602 \\
\hline & $<10 \% \mathrm{PWV}$ & 401.89 & 101.0 & 3.437 & 50.803 & $8.901 \mathrm{E}-04$ & 418.642 \\
\hline \multirow[t]{6}{*}{ Rothera } & all & 301.44 & 160.0 & 1.013 & 95.599 & $5.888 \mathrm{E}-03$ & 50.103 \\
\hline & JJA & 301.44 & 133.5 & 1.183 & 134.399 & $2.660 \mathrm{E}-03$ & 157.448 \\
\hline & DJF & 301.44 & 182.0 & 0.890 & 85.800 & $9.517 \mathrm{E}-03$ & - \\
\hline & day & 301.44 & 165.6 & 0.976 & 93.997 & $6.639 \mathrm{E}-03$ & 35.184 \\
\hline & night & 301.44 & 142.4 & 1.144 & 125.998 & $3.187 \mathrm{E}-03$ & 130.046 \\
\hline & $<10 \% \mathrm{PWV}$ & 301.44 & 77.5 & 1.794 & 121.402 & $9.114 \mathrm{E}-04$ & 341.717 \\
\hline \multirow[t]{6}{*}{ Thule } & all & 301.44 & 133.2 & 1.247 & 94.397 & $3.404 \mathrm{E}-03$ & 123.826 \\
\hline & JJA & 301.44 & 198.9 & 0.724 & 89.600 & $1.490 \mathrm{E}-02$ & - \\
\hline & DJF & 301.44 & 62.2 & 1.949 & 93.601 & $9.017 \mathrm{E}-04$ & 337.858 \\
\hline & day & 301.44 & 154.6 & 1.074 & 92.600 & $5.261 \mathrm{E}-03$ & 64.568 \\
\hline & night & 301.44 & 73.3 & 1.783 & 96.799 & $1.124 \mathrm{E}-03$ & 298.869 \\
\hline & $<10 \% \mathrm{PWV}$ & 401.88 & 102.2 & 2.706 & 101.398 & $8.486 \mathrm{E}-04$ & 475.841 \\
\hline
\end{tabular}

based receivers; however, other less well-known species with overlapping lines could introduce random errors, particularly ones with comparable line intensities and/or close proximity to the target signal, necessitating prior screening.

A summary of the results for all locations is tabulated in Tables 5, 6, 7 and 8, with associated minimum measurement integration times and maximum receiver noise temperatures. The latter is based on an integration time of $30 \mathrm{~min}$ which, for most of the brominated scenarios and some of the $\mathrm{HO}_{2}$ cases, is insufficient to detect the signal of the species above the background noise with a signal-to-noise ratio of two (cases indicated with a dash). As the simulations use averaged profiles; however, this does not rule out the possibility of detecting these species when they are present at higher abundances.
Within the complete 2012 UM-UKCA data set, comprising 720 profiles each of $\mathrm{HBr}$ and $\mathrm{HOBr}$, concentrations can reach more than 10 times the averaged scenarios at all pressure levels. Furthermore, since field measurements of bromine compounds reveal high temporal variability often associated with unconstrained mechanisms such as blowing snow, frost flowers and newly forming sea ice (Jones et al., 2006), it is unlikely that the model represents the highest extremes of $\mathrm{HBr}$ and $\mathrm{HOBr}$ abundance.

Minimum integration times are of the order of 6 months or longer for $\mathrm{HBr}$ and $\mathrm{HOBr}$, reducing to around $9 \mathrm{~h}$ for $\mathrm{HO}_{2}$ and below $1 \mathrm{~s}$ for $\mathrm{N}_{2} \mathrm{O}$. Even though concentrations of $\mathrm{HBr}$ (and to a lesser extent $\mathrm{HOBr}$ ) are elevated above Antarctica with respect to other latitudes (Fig. 5b), this is not re- 
flected in the relative signal strengths for Halley and Rothera as other factors, such as the higher water vapour concentrations in these locations, eclipse this effect. Greater $\mathrm{HO}_{2}$ signal strengths are seen in the Antarctic austral summer (DJF), relative to those in the Arctic boreal summer (JJA) by a factor of four. Unique to this study, DJF $\mathrm{HO}_{2}$ signals at these locations are even stronger than the corresponding low-humidity case, suggesting time of year is potentially more important than dry conditions for detecting $\mathrm{HO}_{2}$ in Antarctica.

\section{Conclusions}

An updated review of the submillimetre atmosphere has been presented in the light of recent technological developments in the fields of astronomy which could potentially address outstanding challenges in this region. We have developed a methodology for simulating clear-sky submillimetre (10$2000 \mathrm{GHz})$ atmospheric spectra by combining an existing, validated radiative transfer code with careful construction of atmospheric climatologies for selected locations. We have demonstrated how the choice of spectral lines for groundbased remote sensing depends strongly on atmospheric conditions at the individual locations. Significant differences have been found in the spectroscopic line data in two of the main reference databases, and between different water vapour continuum models, highlighting the need for improved theoretical and experimental spectroscopic data for remote sensing and climate studies in the submillimetre region. The optimal frequencies for measuring $\mathrm{HBr}, \mathrm{HOBr}$, $\mathrm{HO}_{2}$ and $\mathrm{N}_{2} \mathrm{O}$ from the ground, at the zero zenith angle, have been determined and preliminary receiver characteristics calculated and tabulated for all considered locations and scenarios.

The brightness temperature, centre frequency, and width of the submillimetre spectral peaks produced by each of the four selected atmospheric trace gases show dependence on site, season and ambient water vapour concentration, reenforcing the need to quantify the full possible variability in measurements prior to instrument design. Signal selection should also be informed by screening for overlapping spectral lines from neighbouring species, which is particularly important if the line falls within the bandwidth of the target signal and/or is of comparable intensity, or if the species concentration cannot be well estimated. This highlights the merits of developing instruments with multiple channels throughout the submillimetre range as it can be beneficial to observe many lines at different frequencies simultaneously. The ARTS code used to perform these simulations calculates intensities at each point on the frequency grid by summing the spectral line absorption from the lineshape at that frequency, for every line within the specified cut-off. Therefore, if a line with a particularly small half width has a central frequency that falls directly within grid points it will contribute very little to either of the two surrounding frequencies. While the initial survey to find the position of the strongest lines was found to be robust on a frequency grid of $0.5 \mathrm{GHz}$ for the cases chosen, it is recommended that similar surveys be performed at as high a resolution as possible within computational limits, in order to ensure every line is screened for. The sample molecules characterised span a range of detectability. The simulations suggest that the bromine compounds $\mathrm{HBr}$ and $\mathrm{HOBr}$ would be particularly challenging to observe. For the given zero zenith angle, non-inclusion of (unknown) receiver system errors and overlapping signals from astronomical sources, this essentially presents the upper limit of the detectability, suggesting particular combinations of locations and species would be unfavourable for instrument deployment. These results are informative to those considering potential future submillimetre spectroscopy campaigns. However, promising candidate channels are identified for measuring $\mathrm{N}_{2} \mathrm{O}, \mathrm{HO}_{2}$ and even $\mathrm{HBr}$ which is on the limit of detection, given long integration times and sensitive instruments such as those developed for astronomical applications.

As the results of this work are based on radiative transfer forward model output, a rigorous approach was adopted to estimate its major uncertainties and capture the true behaviour of the atmosphere. Atmospheric climatologies representative of real atmospheric conditions at different sites were created by sourcing in situ observational data sets, local to each of the selected sites, to append to high elevation reanalysis profiles. Uncertainties in the simulation parameters have been investigated by comparing different spectroscopic line databases and continuum parameterisations. Though differences in line intensities between the HITRAN database and JPL catalogue are small, the wider issues relating to inclusion of lines identified for $\mathrm{HOBr}$ and $\mathrm{N}_{2} \mathrm{O}$ suggests that these catalogues are in need of improvement to facilitate studies such as this one, particularly for gases with low atmospheric concentrations. Further laboratory work carried out by the spectroscopic community would give greater confidence in simulating atmospheric radiative transfer in the submillimetre region and its application to remote sensing and climate studies. Additionally, as the details of lower-energy regions are often neglected in energy budget studies there is a dearth of radiative closure studies in the submillimetre, hence the large contribution by the water vapour continuum in this region remains largely unvalidated. Filling this gap necessitates a hyperspectral instrument that measures across a broad range of frequencies to be either constructed or repurposed by collaborating with the astronomical sciences.

A strategy has been established in this study to determine the measurement potential of various atmospheric gases at hitherto largely unexploited wavelengths. This strategy can be applied to other species of interest in the terrestrial atmosphere, of which there are many with spectral signatures in the submillimetre, including ice clouds, which have not been investigated in the current work but could be incorporated in future studies using the cloud parameterisations available in radiative transfer codes. The initial results presented here can 
be taken forward by applying inversion algorithms to retrieve vertical gas concentrations and provide a framework to guide future instrument design. This work shows that it is in principle possible to do important atmospheric science from the ground at polar latitudes, with astronomical instruments.

\section{Data availability}

The majority of the atmospheric data were obtained from the ECMWF (2016) data repository available publicly at http: //apps.ecmwf.int/datasets/. This provides the model atmospheric profiles. Observational datasets were obtained from various sources, which are referenced in Table 1. Line data were obtained from the HITRAN (2016) database at https: //www.cfa.harvard.edu/hitran/.

Acknowledgements. This work, carried out as part of the SPECTRO-ICE project at the University of Cambridge and the British Antarctic Survey (BAS), was supported by UK Higher Education Innovation funding for E. C. Turner and R. Clancy. D. A. Newnham and A. E. Jones, were supported in part by the UK's Natural Environment Research Council. We thank Michael Simmons for his contributions to the SPECTRO-ICE project, Xin Yang (BAS) for producing UKCA model data, and Patrick Eriksson, Stefan Buehler and Jana Mendrok for providing guidance for using the ARTS radiative transfer model. Peter Kirsch provided computer support for running ARTS at BAS. The authors gratefully acknowledge two anonymous reviewers for their constructive comments.

Edited by: T. von Clarmann

Reviewed by: two anonymous referees

\section{References}

Abbatt, J. P. D., Thomas, J. L., Abrahamsson, K., Boxe, C., Granfors, A., Jones, A. E., King, M. D., Saiz-Lopez, A., Shepson, P. B., Sodeau, J., Toohey, D. W., Toubin, C., von Glasow, R., Wren, S. N., and Yang, X.: Halogen activation via interactions with environmental ice and snow in the polar lower troposphere and other regions, Atmos. Chem. Phys., 12, 6237-6271, doi:10.5194/acp-12-6237-2012, 2012

Anderson, G. P., Clough, S., Kneizys, F., Chetwynd, J., and Shettle, E. P.: AFGL atmospheric constituent profiles $(0-120 \mathrm{~km})$, Tech. rep., DTIC Document, 1986.

Arnold, K., Ade, P., Anthony, A., Aubin, F., Boettger, D., Borrill, J., Cantalupo, C., Dobbs, M., Errard, J., and Flanigan, D.: Millimeter, Submillimeter, and Far-Infrared Detectors and Instrumentation for Astronomy V, in: Proc. SPIE, vol. 7741, 77411E, 2010.

Benford, D., Hunter, T., and Phillips, T.: Noise equivalent power of background limited thermal detectors at submillimeter wavelengths, Int. J. Infrared Milli., 19, 931-938, 1998.

Buehler, S., Eyring, V., and Kuellmann, H.: The impact of continuum emissions in the $\mathrm{mm}$ and sub-mm spectral range, $\mathrm{CON}$ TRACTOR REPORT-EUROPEAN SPACE AGENCY CR P, 1230, 1996
Buehler, S., Eriksson, P., Kuhn, T., Von Engeln, A., and Verdes, C.: ARTS, the atmospheric radiative transfer simulator, J. Quant. Spectrosc. Ra., 91, 65-93, 2005.

Buehler, S., Jimenez, C., Evans, K., Eriksson, P., Rydberg, B., Heymsfield, A., Stubenrauch, C., Lohmann, U., Emde, C., John, V. O., Sreerekha, T. R., and Davis, C. P.: A concept for a satellite mission to measure cloud ice water path, ice particle size, and cloud altitude, Q. J. Roy. Meteor. Soc., 133, 109-128, 2007.

Buehler, S. A., Defer, E., Evans, F., Eliasson, S., Mendrok, J., Eriksson, P., Lee, C., Jiménez, C., Prigent, C., Crewell, S., Kasai, Y., Bennartz, R., and Gasiewski, A. J.: Observing ice clouds in the submillimeter spectral range: the CloudIce mission proposal for ESA's Earth Explorer 8, Atmos. Meas. Tech., 5, 1529-1549, doi:10.5194/amt-5-1529-2012, 2012.

Chamberlin, R. A., Martin, R. N., Martin, C. L., and Stark, A. A.: Submillimeter atmospheric FTS at the geographic South Pole, in: Astronomical Telescopes and Instrumentation, International Society for Optics and Photonics, 609-620, 2003.

Charlton, J., Buehler, S., Defer, E., Prigent, C., Moyna, B., Lee, C., de Maagt, P., and Kangas, V.: A sub-millimetre wave airborne demonstrator for the observation of precipitation and ice clouds, in: Geoscience and Remote Sensing Symposium, 2009 IEEE International, IGARSS 2009, vol. 3, pp. III-1023, IEEE, 2009.

Chung, E.-S., Soden, B., Sohn, B., and Shi, L.: Upper-tropospheric moistening in response to anthropogenic warming, P. Natl. Acad. Sci. USA, 111, 11636-11641, 2014.

Clancy, R. T., Sandor, B. J., Rusch, D. W., and Muhleman, D. O.: Microwave observations and modeling of $\mathrm{O}_{3}, \mathrm{H}_{2} \mathrm{O}$, and $\mathrm{HO}_{2}$ in the mesosphere, J. Geophys. Res.-Atmos. (1984-2012), 99, 5465-5473, 1994.

Clough, S., Kneizys, F., and Davies, R.: Line shape and the water vapor continuum, Atmos. Res., 23, 229-241, 1989.

Clough, S., Brown, P., Miller, N., Liljegren, J., and Shippert, T.: Residual analysis of surface spectral radiances between instrument observations and line-by-line calculations, in: Proceedings of the Fourth Atmospheric Radiation Measurement (ARM) science team meeting, March 1994, Charleston, SC, USA, 1994.

Clough, S., Shephard, M., Mlawer, E., Delamere, J., Iacono, M., Cady-Pereira, K., Boukabara, S., and Brown, P.: Atmospheric radiative transfer modeling: a summary of the AER codes, J. Quant. Spectrosc. Ra., 91, 233-244, 2005.

Dee, D., Uppala, S., Simmons, A., Berrisford, P., Poli, P., Kobayashi, S., Andrae, U., Balmaseda, M., Balsamo, G., Bauer, P., Bechtold, P., Beljaars, A. C. M., van de Berg, L., Bidlot, J., Bormann, N., Delsol, C., Dragani, R., Fuentes, M., Geer, A. J., Haimberger, L., Healy, S. B., Hersbach, H., Hólm, E. V., Isaksen, L., Kållberg, P., Köhler, M., Matricardi, M., McNally, A. P., Monge-Sanz, B. M., Morcrette, J.-J., Park, B.-K., Peubey, C., de Rosnay, P., Tavolato, C., Thépaut, J.-N., and Vitart, F.: The ERA-Interim reanalysis: Configuration and performance of the data assimilation system, Q. J. Roy. Meteor. Soc., 137, 553-597, 2011.

Delamere, J., Clough, S., Payne, V., Mlawer, E., Turner, D., and Gamache, R.: A far-infrared radiative closure study in the Arctic: Application to water vapor, J. Geophys. Res.-Atmos., 115, D17106, doi:10.1029/2009JD012968, 2010.

Duncan, W. D., Holland, W. S., Withington, S., and Zmuidzinas, J.: Millimeter and Submillimeter Detectors and Instrumentation for Astronomy IV, Proc. SPIE, 2008. 
ECMWF: Atmospheric data, available at: http://apps.ecmwf.int/ datasets/, last access: 14 November 2016.

Ekström, M., Eriksson, P., Rydberg, B., and Murtagh, D. P.: First Odin sub-mm retrievals in the tropical upper troposphere: humidity and cloud ice signals, Atmos. Chem. Phys., 7, 459-469, doi:10.5194/acp-7-459-2007, 2007.

Eriksson, P., Buehler, S., Davis, C., Emde, C., and Lemke, O.: ARTS, the atmospheric radiative transfer simulator, version 2, J. Quant. Spectrosc. Ra., 112, 1551-1558, 2011.

Esposito, F., Grieco, G., Leone, L., Restieri, R., Serio, C., Bianchini, G., Palchetti, L., Pellegrini, M., Cuomo, V., Masiello, G., and Pavese, G.: REFIR/BB initial observations in the water vapour rotational band: Results from a field campaign, J. Quant. Spectrosc. Ra., 103, 524-535, 2007.

Evans, K. F., Evans, A. H., Nolt, I. G., and Marshall, B. T.: The prospect for remote sensing of cirrus clouds with a submillimeter-wave spectrometer, J. Appl. Meteorol., 38, 514$525,1999$.

Fox, C., Green, P. D., Pickering, J. C., and Humpage, N.: Analysis of far-infrared spectral radiance observations of the water vapor continuum in the Arctic, J. Quant. Spectrosc. Ra., 155, 57-65, 2015.

Frisk, U., Hagström, M., Ala-Laurinaho, J., Andersson, S., Berges, J.-C., Chabaud, J.-P., Dahlgren, M., Emrich, A., Florén, H.-G., Florin, G., Fredrixon, M., Gaier, T., Haas, R., Hirvonen, T., Hjalmarsson, ̊̊., Jakobsson, B., Jukkala, P., Kildal, P. S., Kollberg, E., Lassing, J., Lecacheux, A., Lehikoinen, P., Lehto, A., Mallat, J., Marty, C., Michet, D., Narbonne, J., Nexon, M., Olberg, M., Olofsson, A. O. H., Olofsson, G., Origné, A., Petersson, M., Piironen, P., Pons, R., Pouliquen, D., Ristorcelli, I., Rosolen, C., Rouaix, G., Räisänen, A. V., Serra, G., Sjöberg, F., Stenmark, L., Torchinsky, S., Tuovinen, J., Ullberg, C., Vinterhav, E., Wadefalk, N., Zirath, H., Zimmermann, P., and Zimmermann, R.: The Odin satellite-I. Radiometer design and test, Astron. Astrophys., 402, L27-L34, 2003.

Froidevaux, L., Livesey, N. J., Read, W. G., Jiang, Y. B., Jimenez, C., Filipiak, M. J., Schwartz, M. J., Santee, M. L., Pumphrey, H. C., Jiang, J. H., Wu, D. L., Manney, G. L., Drouin, B. J., Waters, J. W., Fetzer, E. J., Bernath, P. F., Boone, C. D., Walker, K. A., Jucks, K. W., Toon, G. C., Margitan, J. J., Sen, B., Webster, C. R., Christensen, L. E., Elkins, J. W., Atlas, E., Lueb, R. A., and Hendershot, R.: Early validation analyses of atmospheric profiles from EOS MLS on the Aura satellite, IEEE Geosci. Remote S., 44, 1106-1121, 2006.

Giovanelli, R., Darling, J., Henderson, C., Hoffman, W., Barry, D., Cordes, J., Eikenberry, S., Gull, G., Keller, L., Smith, J., and Stacey, G.: The optical/infrared astronomical quality of high Atacama sites. II., Infrared characteristics, Publ. Astron. Soc. Pac., 113, 803-813, 2001.

Green, P. D., Newman, S. M., Beeby, R. J., Murray, J. E., Pickering, J. C., and Harries, J. E.: Recent advances in measurement of the water vapour continuum in the far-infrared spectral region, Philos. T. R. Soc. A, 370, 2637-2655, 2012.

Hansen, J., Sato, M., Kharecha, P., and von Schuckmann, K.: Earth's energy imbalance and implications, Atmos. Chem. Phys., 11, 13421-13449, doi:10.5194/acp-11-13421-2011, 2011.

Harries, J.: Submillimeter wave spectroscopy of the atmosphere, JOSA, 67, 880-893, 1977.
Harries, J.: Atmospheric radiometry at submillimeter wavelengths, Appl. Optics, 19, 3075-3081, 1980.

Harries, J., Carli, B., Rizzi, R., Serio, C., Mlynczak, M., Palchetti, L., Maestri, T., Brindley, H., and Masiello, G.: The far-infrared Earth, Rev. Geophys., 46, RG4004, doi:10.1029/2007RG000233, 2008.

Hayton, D. and Ade, P.: Development of CILCO, a novel instrument for remote sensing of cirrus clouds in the far-infrared/submillimetre, in: Infrared and Millimeter Waves, 2007 and the 2007 15th International Conference on Terahertz Electronics. IRMMW-THz, Joint 32nd International Conference on, 333334, IEEE, 2007.

HITRAN: Line data, available at: https://www.cfa.harvard.edu/ hitran/, last access: 14 November 2016.

Holland, W. S. and Zmuidzinas, J.: Millimeter, Submillimeter, and Far-Infrared Detectors and Instrumentation for Astronomy VI, in: Proc. of SPIE Vol, vol. 8452, 845201, doi:10.1117/12.1000040, 2012.

Holland, W. S. and Zmuidzinas, J.: Millimeter, Submillimeter, and Far-Infrared Detectors and Instrumentation for Astronomy VII, in: Proc. of SPIE Vol, vol. 9153, 915301, doi:10.1117/12.2075309, Montréal, Quebec, Canada, 2014.

Inness, A., Baier, F., Benedetti, A., Bouarar, I., Chabrillat, S., Clark, H., Clerbaux, C., Coheur, P., Engelen, R. J., Errera, Q., Flemming, J., George, M., Granier, C., Hadji-Lazaro, J., Huijnen, V., Hurtmans, D., Jones, L., Kaiser, J. W., Kapsomenakis, J., Lefever, K., Leitão, J., Razinger, M., Richter, A., Schultz, M. G., Simmons, A. J., Suttie, M., Stein, O., Thépaut, J.-N., Thouret, V., Vrekoussis, M., Zerefos, C., and the MACC team: The MACC reanalysis: an 8 yr data set of atmospheric composition, Atmos. Chem. Phys., 13, 4073-4109, doi:10.5194/acp-13-4073-2013, 2013.

Jiménez, C., Buehler, S., Rydberg, B., Eriksson, P., and Evans, K.: Performance simulations for a submillimetre-wave satellite instrument to measure cloud ice, Q. J. Roy. Meteor. Soc., 133, 129149, 2007.

Jiménez, C., Gulkis, S., Beaudin, G., Encrenaz, T., Eriksson, P., Kamp, L., Lee, S., Buehler, S., and the MIRO team: Submillimeter observations of the terrestrial atmosphere during an Earth flyby of the MIRO sounder on the Rosetta spacecraft, Planet. Space Sci., 82, 99-112, 2013.

Jones, A., Anderson, P., Wolff, E., Turner, J., Rankin, A., and Colwell, S.: A role for newly forming sea ice in springtime polar tropospheric ozone loss? Observational evidence from Halley station, Antarctica, J. Geophys. Res.-Atmos., 111, D08306, doi:10.1029/2005JD006566, 2006.

Kasai, Y. J., Urban, J., Takahashi, C., Hoshino, S., Takahashi, K., Inatani, J., Shiotani, M., and Masuko, H.: Stratospheric ozone isotope enrichment studied by submillimeter wave heterodyne radiometry: the observation capabilities of SMILES, IEEE Geosci. Remote S., 44, 676-693, 2006.

Kikuchi, K.-I., Nishibori, T., Ochiai, S., Ozeki, H., Irimajiri, Y., Kasai, Y., Koike, M., Manabe, T., Mizukoshi, K., Murayama, Y., Nagahama, T., Sano, T., Sato, R., Seta, M., Takahashi, C., Takayanagi, M., Masuko, H., Inatani, J., Suzuki, M., and Shiotani, M.: Overview and early results of the Superconducting Submillimeter-Wave Limb-Emission Sounder (SMILES), J. Geophys. Res.-Atmos., 115, D23306, doi:10.1029/2010JD014379, 2010. 
Koga, Y., Takeo, H., Kondo, S., Sugie, M., Matsumura, C., McRae, G., and Cohen, E.: The rotational spectra, molecular structure, dipole moment, and hyperfine constants of $\mathrm{HOBr}$ and $\mathrm{DOBr}$, J. Mol. Spectrosc., 138, 467-481, 1989.

Kraus, J. D.: Radio astronomy, McGraw-Hill, New York, USA, 496 pp., 1966.

Kuntz, M.: A new implementation of the Humlicek algorithm for the calculation of the Voigt profile function, J. Quant. Spectrosc. Ra., 57, 819-824, 1997.

Liao, J., Huey, L., Tanner, D., Flocke, F., Orlando, J., Neuman, J., Nowak, J., Weinheimer, A., Hall, S., Smith, J., Fried, A., Staebler, R. M., Wang, Y., Koo, J.-H., Cantrell, C. A., Weibring, P., Walega, J., Knapp, D. J., Shepson, P. B., and Stephens, C. R.: Observations of inorganic bromine $\left(\mathrm{HOBr}, \mathrm{BrO}\right.$, and $\left.\mathrm{Br}_{2}\right)$ speciation at Barrow, Alaska, in spring 2009, J. Geophys. Res.-Atmos., 117, D00R16, doi:10.1029/2011JD016641, 2012.

Liebe, H., Hufford, G., and Cotton, M.: Propagation modeling of moist air and suspended water/ice particles at frequencies below $1000 \mathrm{GHz}$, in: AGARD, Atmospheric Propagation Effects Through Natural and Man-Made Obscurants for Visible to MMWave Radiation 11 p (SEE N94-30495 08-32), vol. 1, 1993.

Liebe, H. J.: MPM - An atmospheric millimeter-wave propagation model, Int. J. Infrared Milli., 10, 631-650, 1989.

Ma, Q. and Tipping, R.: Water vapor millimeter wave foreign continuum: a Lanczos calculation in the coordinate representation, J. Chem. Phys., 117, 10581-10596, 2002.

Manago, N., Ozeki, H., and Suzuki, M.: Band selection study for the sub-mm limb sounder, SMILES-2, in: Geoscience and Remote Sensing Symposium (IGARSS), 2014 IEEE International, 41534156, IEEE, 2014.

Marshall, J., Armour, K. C., Scott, J. R., Kostov, Y., Hausmann, U., Ferreira, D., Shepherd, T. G., and Bitz, C. M.: The ocean's role in polar climate change: asymmetric Arctic and Antarctic responses to greenhouse gas and ozone forcing, Philos. T. R. Soc. A, 372, 20130040, doi:10.1098/rsta.2013.0040, 2014.

Masiello, G., Serio, C., Esposito, F., and Palchetti, L.: Validation of line and continuum spectroscopic parameters with measurements of atmospheric emitted spectral radiance from far to mid infrared wave number range, J. Quant. Spectrosc. Ra., 113, 1286-1299, 2012.

Matsushita, S. and Matsuo, H.: FTS Measurements of Submillimeter-Wave Atmospheric Opacity at Pampa la Bola: III. Water Vapor, Liquid Water, and $183 \mathrm{GHz}$ Water Vapor Line Opacities, Publ. Astron. Soc. Jpn., 55, 325-333, 2003.

McConnell, J., Henderson, G., Barrie, L., Bottenheim, J., Niki, H., Langford, C., and Templeton, E.: Photochemical bromine production implicated in Arctic boundary-layer ozone depletion, Nature, 355, 150-152, 1992.

Melsheimer, C., Verdes, C., Buehler, S., Emde, C., Eriksson, P., Feist, D., Ichizawa, S., John, V., Kasai, Y., Kopp, G., Koulev, N., Kuhn, T., Lemke, O., Ochiai, S., Schreier, F., Sreerekha, T. R., Suzuki, M., Takahashi, C., Tsujimaru, S., and Urban, J.: Intercomparison of general purpose clear sky atmospheric radiative transfer models for the millimeter/submillimeter spectral range, Radio Sci., 40, RS1007, doi:10.1029/2004RS003110, 2005.

MetOffice: Met Office Global Radiosonde Data, NCAS British Atmospheric Data Centre, MetOffice, available at: http://catalogue. ceda.ac.uk/uuid/f2afaf808b61394b78bd342ff068c8cd (last access: September 2015), 2006.
Millán, L., Wang, S., Livesey, N., Kinnison, D., Sagawa, H., and Kasai, Y.: Stratospheric and mesospheric $\mathrm{HO}_{2}$ observations from the Aura Microwave Limb Sounder, Atmos. Chem. Phys., 15, 2889-2902, doi:10.5194/acp-15-2889-2015, 2015.

Miloshevich, L. M., Vömel, H., Whiteman, D. N., Lesht, B. M., Schmidlin, F., and Russo, F.: Absolute accuracy of water vapor measurements from six operational radiosonde types launched during AWEX-G and implications for AIRS validation, J. Geophys. Res.-Atmos., 111, D09S10, doi:10.1029/2005JD006083, 2006.

Mlawer, E. J., Payne, V. H., Moncet, J.-L., Delamere, J. S., Alvarado, M. J., and Tobin, D. C.: Development and recent evaluation of the MT_CKD model of continuum absorption, Philos. T. R. Soc. A, 370, 2520-2556, 2012.

Mlynczak, M., Johnson, D., Bingham, G., Jucks, K., Traub, W., Gordley, L., and Harries, J.: The far-infrared spectroscopy of the troposphere (FIRST) project, in: Proc. SPIE, vol. 5659, 81-87, 2004.

Morgenstern, O., Braesicke, P., O’Connor, F. M., Bushell, A. C., Johnson, C. E., Osprey, S. M., and Pyle, J. A.: Evaluation of the new UKCA climate-composition model - Part 1: The stratosphere, Geosci. Model Dev., 2, 43-57, doi:10.5194/gmd-2-432009, 2009.

NOAA, U. A. F.: US standard atmosphere, 1976, Tech. rep., NOAAS/T, 1976.

Nordh, H., Von Schéele, F., Frisk, U., Ahola, K., Booth, R., Encrenaz, P., Hjalmarson, Å., Kendall, D., Kyrölä, E., Kwok, S., Lecacheux, A., Leppelmeier, G., Llewellyn, E. J., Mattila, K., Mégie, G., Murtagh, D., Rougeron M., and Witt, G.: The Odin orbital observatory, Astron. Astrophys., 402, L21-L25, 2003.

Pachauri, R. K., Allen, M., Barros, V., Broome, J., Cramer, W., Christ, R., Church, J., Clarke, L., Dahe, Q., Dasgupta, P., Dubash, N. K., Edenhofer, O., Elgizouli, I., Field, C. B., Forster, P., Friedlingstein, P., Fuglestvedt, J., Gomez-Echeverri, L., Hallegatte, S., Hegerl, G., Howden, M., Jiang, K., Jimenez Cisneroz, B., Kattsov, V., Lee, H., Mach, K. J., Marotzke, J., Mastrandrea, M. D., Meyer, L., Minx, J., Mulugetta, Y., O’Brien, K., Oppenheimer, M., Pereira, J. J., Pichs-Madruga, R., Plattner, G. K., Pörtner, H. O., Power, S. B., Preston, B., Ravindranath, N. H., Reisinger, A., Riahi, K., Rusticucci, M., Scholes, R., Seyboth, K., Sokona, Y., Stavins, R., Stocker, T. F., Tschakert, P., van Vuuren, D., and van Ypserle, J. P.: Climate Change 2014: Synthesis Report. Contribution of Working Groups I, II and III to the Fifth Assessment Report of the Intergovernmental Panel on Climate Change, 2014.

Paine, S., Blundell, R., Papa, D. C., Barrett, J. W., and Radford, S. J.: A Fourier transform spectrometer for measurement of atmospheric transmission at submillimeter wavelengths, Publ. Astron. Soc. Pac., 112, 108-118, 2000.

Paine, S. N. and Turner, D. D.: Processing and calibration of submillimeter Fourier transform radiometer spectra from the RHUBC-II campaign, IEEE T. Geosci. Remote, 51, 5187-5198, 2013.

Palchetti, L., Bianchini, G., Carli, B., Cortesi, U., and Del Bianco, S.: Measurement of the water vapour vertical profile and of the Earth's outgoing far infrared flux, Atmos. Chem. Phys., 8, 28852894, doi:10.5194/acp-8-2885-2008, 2008.

Pardo, J., Cernicharo, J., and Serabyn, E.: Modeling the atmospheric longwave spectrum: State of the art in the horizon of ALMA, in: 
Astronomical Site Evaluation in the Visible and Radio Range, 266, p. 188, 2002.

Pardo, J., Wiedner, M., Serabyn, E., Wilson, C., Cunningham, C., Hills, R., and Cernicharo, J.: Side-by-side comparison of Fourier transform spectroscopy and water vapor radiometry as tools for the calibration of millimeter/submillimeter ground-based observatories, Astrophys. J. Suppl. S., 153, 363-367, 2004.

Pardo, J. R., Cernicharo, J., and Serabyn, E.: Atmospheric transmission at microwaves (ATM): an improved model for millimeter/submillimeter applications, IEEE T. Antenn. Propag., 49, 1683-1694, 2001a.

Pardo, J. R., Serabyn, E., and Cernicharo, J.: Submillimeter atmospheric transmission measurements on Mauna Kea during extremely dry El Nino conditions: implications for broadband opacity contributions, J. Quant. Spectrosc. Ra., 68, 419-433, 2001b.

Payne, V. H., Mlawer, E. J., Cady-Pereira, K. E., and Moncet, J.L.: Water vapor continuum absorption in the microwave, IEEE T. Geosci. Remote, 49, 2194-2208, 2011.

Phillips, T.: Techniques of submillimeter astronomy, in: Millimetre and Submillimetre Astronomy, Kluwer Academic Publishers, Dordrecht, the Netherlands, 1-25, 1988.

Phillips, T. G. and Zmuidzinas, J.: Millimeter and Submillimeter Detectors for Astronomy, in: Millimeter and Submillimeter Detectors for Astronomy, Proceedings of SPIE Vol 4855, 636 pp., 2003.

Pickett, H., Poynter, R., Cohen, E., Delitsky, M., Pearson, J., and Müller, H.: Submillimeter, millimeter, and microwave spectral line catalog, J. Quant. Spectrosc. Ra., 60, 883-890, 1998.

Podobedov, V., Plusquellic, D., Siegrist, K., Fraser, G., Ma, Q., and Tipping, R.: New measurements of the water vapor continuum in the region from 0.3 to $2.7 \mathrm{THz}$, J. Quant. Spectrosc. Ra., 109, 458-467, 2008.

Prigent, C., Pardo, J. R., and Rossow, W. B.: Comparisons of the millimeter and submillimeter bands for atmospheric temperature and water vapor soundings for clear and cloudy skies, J. Appl. Meteorol. Clim., 45, 1622-1633, 2006.

Ravishankara, A., Daniel, J. S., and Portmann, R. W.: Nitrous oxide $\left(\mathrm{N}_{2} \mathrm{O}\right)$ : the dominant ozone-depleting substance emitted in the 21st century, Science, 326, 123-125, 2009.

Remijan, A.: ALMA Cycle 3 Technical Handbook Version 1.0, ALMA, Santiago, 2015.

Rigopoulou, D., Laing, R., Withington, S., Magdis, G., Graves, S., Richer, J., and Ellison, B.: Report on the Workshop "Science with ALMA Band 11 (1.0-1.6 THz)", The Messenger, 153, 35-37, 2013.

Rosenkranz, P. W.: Water vapor microwave continuum absorption: A comparison of measurements and models, Radio Sci., 33, 919928, 1998

Rothman, L., Gordon, I., Babikov, Y., Barbe, A., Benner, D. C., Bernath, P., Birk, M., Bizzocchi, L., Boudon, V., Brown, L., Camparguej, A., Chancea, K., Coheni, E. A., Coudertk, L. H., Devid, V. M., Drouini, B. J., Faytl, A., Flaudk, J.-M., Gamachem, R. R., Harrisonn, J. J., Hartmannk, J.-M., Hillo, C., Hodgesp, J. T., Jacquemartq, D., Jollyk, A., Lamourouxk, J., Le Royr, R. J., Lia, G., Longp, D. A., Lyulinb, O. M., Mackiea, C. J., Massies, S. T., Mikhailenkob, S., Müllert, H. S. P., Naumenkob, O. V., Nikitinb, A. V., Orphalu, J., Perevalovb, V., Perrink, A., Polovtsevab, E. R., Richarda, C., Smithv, M. A. H., Starikovab, E.,
Sungi, K., Tashkunb, S., Tennysono, J., Tooni, G. C., Tyuterevc, V. G., and Wagnerf, G.: The HITRAN2012 molecular spectroscopic database, J. Quant. Spectrosc. Ra., 130, 4-50, 2013.

Ryan, N. J. and Walker, K. A.: Characterization and simulation of a ground-based millimeter wave observation system for Arctic atmospheric research, J. Quant. Spectrosc. Ra., 151, 26-37, 2015.

Schneider, N., Urban, J., and Baron, P.: Potential of radiotelescopes for atmospheric line observations: I. Observation principles and transmission curves for selected sites, Planet. Space Sci., 57, 1419-1433, 2009.

Schöck, M., Els, S., Riddle, R., Skidmore, W., Travouillon, T., Blum, R., Bustos, E., Chanan, G., Djorgovski, S., Gillett, P., Gregory, B., Nelson, J., Otarola, A., Seguel, J., Vasquez, J., Walker, A., Walker, D., and Wang L.: Thirty Meter Telescope site testing I: overview, Publ. Astron. Soc. Pac., 121, 384-395, 2009.

Serabyn, E., Weisstein, E., Lis, D., and Pardo, J.: Submillimeter Fourier-transform spectrometer measurements of atmospheric opacity above Mauna Kea, Appl. Optics, 37, 2185-2198, 1998.

Serreze, M. C. and Barry, R. G.: Processes and impacts of Arctic amplification: A research synthesis, Global Planet. Change, 77, 85-96, 2011.

Shine, K. P., Ptashnik, I. V., and Rädel, G.: The water vapour continuum: brief history and recent developments, Surv. Geophys., 33, 535-555, 2012.

Shupe, M. D., Turner, D. D., Walden, V. P., Bennartz, R., Cadeddu, M. P., Castellani, B. B., Cox, C. J., Hudak, D. R., Kulie, M. S., Miller, N. B., Neely, R. R., Neff, W. D., and Rowe, P. M.: High and dry: New observations of tropospheric and cloud properties above the Greenland Ice Sheet, B. Am. Meteorol. Soc., 94, 169186, 2013.

Simpson, W. R., von Glasow, R., Riedel, K., Anderson, P., Ariya, P., Bottenheim, J., Burrows, J., Carpenter, L. J., Frieß, U., Goodsite, M. E., Heard, D., Hutterli, M., Jacobi, H.-W., Kaleschke, L., Neff, B., Plane, J., Platt, U., Richter, A., Roscoe, H., Sander, R., Shepson, P., Sodeau, J., Steffen, A., Wagner, T., and Wolff, E.: Halogens and their role in polar boundary-layer ozone depletion, Atmos. Chem. Phys., 7, 4375-4418, doi:10.5194/acp-74375-2007, 2007.

Sirtori, C.: Applied physics: Bridge for the terahertz gap, Nature, 417, 132-133, 2002.

Slocum, D. M., Slingerland, E. J., Giles, R. H., and Goyette, T. M.: Atmospheric absorption of terahertz radiation and water vapor continuum effects, J. Quant. Spectrosc. Ra., 127, 49-63, 2013.

Smith, D. M., Allan, R. P., Coward, A. C., Eade, R., Hyder, P., Liu, C., Loeb, N. G., Palmer, M. D., Roberts, C. D., and Scaife, A. A.: Earth's energy imbalance since 1960 in observations and CMIP5 models, Geophys. Res. Lett., 42, 1205-1213, 2015.

Smith, W. L.: Note on the relationship between total precipitable water and surface dew point, J. Appl. Meteorol., 5, 726-727, 1966.

Stephens, G. L. and L'Ecuyer, T.: The Earth's energy balance, Atmos. Res., 166, 195-203, 2015.

Stephens, G. L., Li, J., Wild, M., Clayson, C. A., Loeb, N., Kato, S., L'Ecuyer, T., Stackhouse Jr., P. W., Lebsock, M., and Andrews, T.: An update on Earth's energy balance in light of the latest global observations, Nat. Geosci., 5, 691-696, 2012.

Thomas, B., Brandt, M., Walber, A., Philipp, M., Gibson, H., Czekala, H., Rose, T., and Kangas, V.: Submillimetre-wave receiver developments for ICI onboard MetOP-SG and ice cloud 
remote sensing instruments, in: Geoscience and Remote Sensing Symposium (IGARSS), 2012 IEEE International, 1278-1281, IEEE, 2012.

Thomas, B., Brandt, M., Walber, A., Gibson, H., Philipp, M., Sonnabend, G., Benzazaa, M., Gonzalez, R., Bergada, M., Martinez, J., Perichaud, M. G., Narhi, T., Klein, U., d'Addio, S., and Kangas, V.: Millimeter \& sub-millimeter wave radiometer instruments for the next generation of polar orbiting meteorological satellite - MetOp-SG, MetOp-SG, unpublished, 2014.

Tobin, D., Best, F., Brown, P., Clough, S., Dedecker, R., Ellingson, R., Garcia, R., Howell, H., Knuteson, R., Mlawer, E., Revercomb, H. E., Short, J. F., van Delst, P. F. W., and Walden, V. P.: Downwelling spectral radiance observations at the SHEBA ice station: Water vapor continuum measurements from 17 to $26 \mu \mathrm{m}$, J. Geophys. Res.-Atmos., 104, 2081-2092, 1999.

Turner, D., Mlawer, E., Bianchini, G., Cadeddu, M., Crewell, S., Delamere, J., Knuteson, R., Maschwitz, G., Mlynczak, M., Paine, S., Palchetti, L., and Tobin, D. C.: Ground-based high spectral resolution observations of the entire terrestrial spectrum under extremely dry conditions, Geophys. Res. Lett., 39, L10801, doi:10.1029/2012GL051542, 2012.

Turner, D. D., Tobin, D., Clough, S. A., Brown, P. D., Ellingson, R. G., Mlawer, E. J., Knuteson, R. O., Revercomb, H. E., Shippert, T. R., Smith, W. L., and Shephard, M. W.: The QME AERI LBLRTM: A closure experiment for downwelling high spectral resolution infrared radiance., J. Atmos. Sci., 61, 2657-2675, 2004.

Turner, D. D., Cadeddu, M. P., Löhnert, U., Crewell, S., and Vogelmann, A. M.: Modifications to the water vapor continuum in the microwave suggested by ground-based $150-\mathrm{GHz}$ observations, IEEE T. Geosci. Remote, 47, 3326-3337, 2009.

Turner, E. C., Lee, H.-T., and Tett, S. F. B.: Using IASI to simulate the total spectrum of outgoing long-wave radiances, Atmos. Chem. Phys., 15, 6561-6575, doi:10.5194/acp-15-65612015, 2015.

Urban, J.: Optimal sub-millimeter bands for passive limb observations of stratospheric $\mathrm{HBr}, \mathrm{BrO}, \mathrm{HOCl}$, and $\mathrm{HO}_{2}$ from space, J. Quant. Spectrosc. Ra., 76, 145-178, 2003.

Urban, J., Lautié, N., Le Flochmoën, E., Jiménez, C., Eriksson, P., de La Noë, J., Dupuy, E., Ekström, M., El Amraoui, L., Frisk, U., Murtagh, D., Olberg, M., and Ricaud, P.: Odin/SMR limb observations of stratospheric trace gases: Level 2 processing of $\mathrm{ClO}$, $\mathrm{N}_{2} \mathrm{O}, \mathrm{HNO}_{3}$, and $\mathrm{O}_{3}$, J. Geophys. Res.-Atmos., 110, D14307, doi:10.1029/2004JD005741, 2005.

Vanek, M. D., Nolt, I. G., Tappan, N. D., Ade, P. A., Gannaway, F. C., Hamilton, P. A., Lee, C., Davis, J. E., and Predko, S.: Far-infrared sensor for cirrus (FIRSC): an aircraft-based Fouriertransform spectrometer to measure cloud radiance, Appl. Optics, 40, 2169-2176, 2001.

Van Vleck, J. and Huber, D.: Absorption, emission, and linebreadths: A semihistorical perspective, Rev. Mod. Phys., 49, 939, doi:10.1103/RevModPhys.49.939, 1977.
Wang, J., Cole, H. L., Carlson, D. J., Miller, E. R., Beierle, K., Paukkunen, A., and Laine, T. K.: Corrections of humidity measurement errors from the Vaisala RS80 radiosonde-Application to TOGA COARE data, J. Atmos. Ocean. Tech., 19, 981-1002, 2002.

Waters, J. W., Froidevaux, L., Harwood, R. S., Jarnot, R. F., Pickett, H. M., Read, W. G., Siegel, P. H., Cofield, R. E., Filipiak, M. J., Flower, D., Holden, J. R., Lau, G. K., Livesey, N. J., Manney, G. L., Pumphrey, H. C., Santee, M. L., Wu, D. L., Cuddy, D. T., Lay, R. R., Loo, M. S., Perun, V. S., Schwartz, M. J., Stek, P. C., Thurstans, R. P., Boyles, M. A., Chandra, K. M., Chavez, M. C., Chen, G.-S., Chudasama, B. V., Dodge, R., Fuller, R. A., Girard, M. A., Jiang, J. H., Jiang, Y., Knosp, B. W., LaBelle, R. C., Lam, J. C., Lee, K. A., Miller, D., Oswald, J. E., Patel, N. C., Pukala, D. M., Quintero, O., Scaff, D. M., Van Snyder, W., Tope, M. C., Wagner, P. A., and Walch, M. J.: The earth observing system microwave limb sounder (EOS MLS) on the Aura satellite, IEEE Geosci. Remote S., 44, 1075-1092, 2006.

Wentz, F. J. and Meissner, T.: Atmospheric absorption model for dry air and water vapor at microwave frequencies below $100 \mathrm{GHz}$ derived from spaceborne radiometer observations, Radio Sci., 51, 381-391, doi:10.1002/2015RS005858, 2016.

Wootten, A. and Thompson, A. R.: The Atacama large millimeter/submillimeter array, Proceedings of the IEEE, 97, 14631471, 2009.

Yang, P., Mlynczak, M. G., Wei, H., Kratz, D. P., Baum, B. A., Hu, Y. X., Wiscombe, W. J., Heidinger, A., and Mishchenko, M. I.: Spectral signature of ice clouds in the far-infrared region: Singlescattering calculations and radiative sensitivity study, J. Geophys. Res.-Atmos., 108, D23311, doi:10.1029/2002JD003291, 2003.

Yang, X., Cox, R. A., Warwick, N. J., Pyle, J. A., Carver, G. D., O'Connor, F. M., and Savage, N. H.: Tropospheric bromine chemistry and its impacts on ozone: A model study, J. Geophys. Res.-Atmos., 110, D23311, doi:10.1029/2005JD006244, 2005.

Yang, X., Pyle, J. A., Cox, R. A., Theys, N., and Van Roozendael, M.: Snow-sourced bromine and its implications for polar tropospheric ozone, Atmos. Chem. Phys., 10, 7763-7773, doi:10.5194/acp-10-7763-2010, 2010

Yang, X., Abraham, N. L., Archibald, A. T., Braesicke, P., Keeble, J., Telford, P. J., Warwick, N. J., and Pyle, J. A.: How sensitive is the recovery of stratospheric ozone to changes in concentrations of very short-lived bromocarbons?, Atmos. Chem. Phys., 14, 10431-10438, doi:10.5194/acp-14-10431-2014, 2014.

Zhang, Y., Seidel, D. J., Golaz, J.-C., Deser, C., and Tomas, R. A.: Climatological Characteristics of Arctic and Antarctic SurfaceBased Inversions*, J. Climate, 24, 5167-5186, 2011.

Zmuidzinas, J., Holland, W. S., Withington, S., and Duncan, W. D.: Millimeter and Submillimeter Detectors and Instrumentation for Astronomy II, in: Proc. SPIE, vol. 5498, p. 30, 2004. 